\title{
Evidence of promising biological-pharmacological activities of the sertraline-based copper complex: $\left(\mathrm{SerH}_{2}\right)_{2}\left[\mathrm{CuCl}_{4}\right]$
}

\author{
Nancy Martini ${ }^{\mathrm{a}}$, Juliana E. Parente ${ }^{\mathrm{a}}$, Maria Eugenia Toledo ${ }^{\mathrm{c}}$, Graciela E. Escudero $^{\mathrm{b}}$, \\ Carlos H. Laino ${ }^{c}$, Juan José Martínez Medina ${ }^{\mathrm{d}}$, Gustavo A. Echeverría ${ }^{\mathrm{e}}$, Oscar E. Piro ${ }^{\mathrm{e}}$, \\ Luis Lezama, ${ }^{\text {f,g }}$, Patricia A.M. Williams ${ }^{\mathrm{a}}$, Evelina G. Ferrer ${ }^{\mathrm{a}, *}$ \\ a Centro de Química Inorgánica (CEQUINOR, CONICET, UNLP), Departamento de Química-Facultad de Ciencias Exactas, Universidad Nacional de La Plata, Boulevard \\ 120 entre 60 y 64, C.C.962-(B1900AVV)-1900 La Plata, Argentina \\ ${ }^{\mathrm{b}}$ Instituto de Farmacia y Bioquímica del CENIIT-UNLaR (Centro de Investigación e Innovación Tecnológica), Av Luis Vernet y Apostol Felipe, 5300 La Rioja, Argentina \\ ${ }^{c}$ Instituto de Biotecnología del CENIIT-UNLaR (Centro de Investigación e Innovación Tecnológica), Av Luis Vernet y Apostol Felipe, 5300, La Rioja, Argentina \\ d Universidad Nacional del Chaco Austral, Comandante Fernández 755, CP: 3700 Presidencia Roque Sáenz Peña, Chaco, Argentina \\ e Departamento de Física, Facultad de Ciencias Exactas, Universidad Nacional de La Plata and IFLP (CONICET, CCT-La Plata), C.C. 67, 1900 La Plata, Argentina \\ ${ }^{\mathrm{f}}$ Departamento de Química Inorgánica, Facultad de Ciencia y Tecnología, Universidad del País Vasco UPV/EHU, PO Box 644, 48080 Bilbao, Spain \\ ${ }^{g}$ BCMaterials, Parque científico y Tecnológico de Bizkaia, Edificio 500-1, 48160 Derio, Spain
}

\section{A R T I C L E I N F O}

\section{Keywords:}

Drug design

X-ray crystal structure

Pharmacological activities

Bioavailability

\begin{abstract}
A B S T R A C T
In the current study the ability of copper complex to exert multiple biological activities is combined with the pharmacological action of sertraline $\left(\mathrm{SerH}_{2} \mathrm{Cl}\right.$, antidepressant drug). The hydrated and anhydrous forms of the tetrachlorocuprate(II) salts, namely $\left(\mathrm{SerH}_{2}\right)_{2}\left[\mathrm{CuCl}_{4}\right] \cdot \frac{1}{2} \mathrm{H}_{2} \mathrm{O}$ and $\left(\mathrm{SerH}_{2}\right)_{2}\left[\mathrm{CuCl}_{4}\right]$, were synthesized and characterized by physicochemical methods. The crystal structures were determined by X-ray diffraction methods. The hydrate complex crystallizes in the monoclinic $P 2_{1}$ space group with $a=8.0807(2) \AA, b=36.2781(8) \AA$, $c=12.6576(3) \AA, \beta=95.665(2)^{\circ}$, and $Z=4$ molecules per unit cell and the un-hydrate in $P 2_{1}$ with $a=13.8727(6) \AA, b=7.5090(3) \AA, c=18.618(1) \AA, \beta=104.563(6)^{\circ}$, and $Z=2$. It has been suggested that $\mathrm{Cu}(\mathrm{II})$ ions might be critical in the development of mood disorders, showed potent biocidal activity, and also acted as analgesic adjuvant. To improve sertraline efficiency, the antidepressant and analgesic activities of the complex have been assessed in rats denoting a marked synergistic effect. Antithyroid and antimicrobial activities were also evaluated. Because depressive disorders and hyperthyroidism diseases led to an oxidative stress state, antioxidant capability has also been tested. The complex behaved as a good superoxide radical scavenger $\left(\mathrm{IC}_{50}=6.3 \times 10^{-6} \mathrm{M}\right)$. The ability of the complex to act as bromoperoxidase mimic was assessed. A pseudofirst order constant of $k=0.157 \pm 0.007 \mathrm{~min}^{-1}$ has been determined. The complex evidences promising biological-pharmacological activities and the albumin binding studies showed a $\mathrm{K}_{\mathrm{b}}$ of $2.90 \times 10^{3} \mathrm{M}^{-1}$ showing an improvement in the uptake of sertraline by albumin at $8 \mathrm{~h}$ incubation (time required for effective interaction of sertraline with the protein).
\end{abstract}

\section{Introduction}

Medicinal inorganic chemistry has become a research area of great interest. It comprises many anticancer agents, antibiotics, antibacterials, antivirals, antiparasitics, antiarthritics, and radiosensitizing agents, among others [1]. Indeed, metal-based drugs offer an alternative therefore impacting strongly over the human health since the discovery of the antitumor activity of cisplatin. The advantage of this kind of new compounds is based in the fact that the changes in the coordination sphere affect the uptake, biodistribution, and metabolism.
They are different from the organic drugs and result in other active metal-containing complex with improved beneficial action [[1,2].].

Among many metal complexes, the copper complexes are well recognized because of their biological action as anticancer [3], antimicrobials [4], and antioxidant agents [5]. However, different salts of tetrachlorocuprate(II) have not yet been thoroughly studied in relation to their biological properties. Usually, these complexes were studied because of the interest in their thermocromic behavior [6], magnetic properties [7], polymorphism [8], and catalytic properties [9].

In recent years we have investigated the antidepressant activity of

\footnotetext{
* Corresponding author.

E-mail address: evelina@quimica.unlp.edu.ar (E.G. Ferrer).
} 
compounds containing typical antidepressant (sertraline) or antioxidants. They include studies on coordination Zn(II) complexes [10-12]. aimed to improve their efficiency. Recently, the involvement of essential elements in depression have been reviewed, resulting in detailed information about preclinical and clinical data which links them with mental disorders, the nutrient in a diet, serum levels, etc. $[13,14]$. Furthermore, information about elements that exert antidepressant or anxiolytic effects when they are administered as simple salts or in combine treatments has been compiled. Indeed, it has been suggested that $\mathrm{Cu}(\mathrm{II})$, as a regulator of several biological process, might be critical in the development of mood disorders. Although there are contradictory results, literature shows that $\mathrm{Cu}$ (II) deficiency in mice, rats and lambs results in significant decreases in brain noradrenaline levels involved in the pathophysiology of depression. In addition, in some antidepressant treatments the serum copper levels were significantly reduced [14]. Considering this information, one of our initial hypotheses was that the new sertraline-based copper complex may behave as a good antidepressant. It might avoid reduction of the copper levels and result in a synergistic effect, which is provoked by the combination of this metal with the antidepressant. As an additional contribution of the present work, the antinociceptive activity of the $\left(\mathrm{SerH}_{2}\right)_{2}\left[\mathrm{CuCl}_{4}\right]$ (Sertralonium tetrachlorocuprate(II)) was evaluated keeping in mind the reported analgesic properties of antidepressants and the one showed by copper complexes $[15,16]$.

Other pharmacological studies that are currently carried out in our group are related to the development of compounds which can potentially act as antithyroid agents and the study of their mechanism of action. These compounds may either act by interfering with thyroid peroxidase (TPO) enzyme or by forming stable complexes with iodine. The formation of stable charge-transfer complexes with the compound of our interest and the iodine molecule were studied at the beginning of our research. In this context, a series of methimazole-derived complexes were considered, as well as the demonstration that sertraline efficiently acted as an iodine captor $[17,18]$. According to these considerations, the determination of the antithyroid activity of the sertraline-derived complex and lactoperoxidase inhibition experiments were measured.

It is worth noting that there seems to be a link between the depressive disorder with both hyperthyroidism diseases and oxidative stress. In both cases, there is an increment in the reactive oxygen species (ROS) and interference in the superoxide dismutase function $[19,20]$. Therefore, it would be very interesting to see if copper complex could also scavenge free radicals. To this purpose, we evaluated the antioxidant activity of the complex.

Considering that some antidepressants (including both sertraline and copper) displayed antimicrobial activities, we also tested if the new compound was able to present and/or improve this behavior [21,22].

In addition, tetrachlorocuprate complex ions have been widely used as catalyst-reaction media in a variety of hydrocarbon conversions, such as chlorinations, oxychlorinations, oxidations and oxidative dehydrogenations $[23,24]$. They have also been used in other catalytic reactions in which the alkane, alkene were obtained as products. For this reason, the transition metal salts were used together with the Grignard reagent [25]. Thus, there is an intrinsic possibility that the complex behaves as a biological catalyst. Bearing in mind this possibility, the mimicking of the peroxidase activity was also evaluated for this compound.

Finally, since the ability of drugs to bind or interact with albumin is essential for their pharmacokinetic and pharmacodynamic properties, the bovine serum albumin ability of binding to the compound was assessed by fluorescence and UV-Vis spectroscopies.

\section{Experimental section}

\subsection{Methods and materials}

$\mathrm{CuCl}_{2} \cdot 2 \mathrm{H}_{2} \mathrm{O}$ was obtained from Biopack (Bs As, Argentina) and sertraline hydrochloride $\left(\mathrm{C}_{17} \mathrm{H}_{17} \mathrm{Cl}_{2} \mathrm{~N}, \quad \mathrm{SerH}_{2}{ }^{+} \mathrm{Cl}^{-}\right)$from Sigma Chemical Company (St. Louis, MO). All the solvents used were from analytical grade and used as supplied. Elemental analysis for carbon, nitrogen and hydrogen was performed using a Carlo Erba EA1108 analyzer. A Shimadzu system (model TG-50 and DTA-50), working in an oxygen flow of $50 \mathrm{~mL} \cdot \mathrm{min}^{-1}$ and at a heating rate of $10^{\circ} \mathrm{C} \cdot \mathrm{min}^{-1}$ has been used for the thermogravimetric analysis. Sample quantities ranged between 10 and $20 \mathrm{mg}$. $\mathrm{Al}_{2} \mathrm{O}_{3}$ was used as a DTA standard.

FTIR spectra of powdered samples as pressed $\mathrm{KBr}$ pellets were measured with a Bruker IFS 66 FTIR-spectrophotometer in the $4000-400 \mathrm{~cm}^{-1}$ frequency range. Spectra were recorded with a frequency resolution of $4 \mathrm{~cm}^{-1}$ and 64 scans were averaged for each spectrum. The data were analyzed using OPUS program (Bruker Optics, USA).

Raman spectra were collected on a Raman Horiba Jobin Yvon T64000 (confocal microscopy Olympus BX41) spectrophotometer with a laser power of $400 \mathrm{~mW}$ and a spectral resolution of $4 \mathrm{~cm}^{-1}$. Each spectrum was obtained as an average of 10 scans collected in the $4000-400 \mathrm{~cm}^{-1}$ range. Spectra plotting, processing, normalizations, manipulations, and evaluation were carried out with the OPUS software (Bruker Optics, Germany). A EPR Bruker ESP300 spectrometer operating at the X-band and equipped with standard Oxford Instruments low-temperature devices (ESR900/ITC4) was used to record the spectrum of the solid state complex at different temperatures. Anisotropic X and Q band EPR spectra of the solid were recorded between 290 and $5 \mathrm{~K}$. A computer simulation of the EPR spectra was performed using the program WINEPR SimFonia (version 1.25, Bruker Analytische Messtecnik, 1996). Magnetic susceptibility measurements on polycrystalline samples were performed also in the $290-5 \mathrm{~K}$ temperature range with a Quantum Design MPMS-7 superconducting quantum interference device magnetometer and using an applied field of $0.1 \mathrm{~T}$. Diamagnetic corrections of the constituent atoms were estimated from Pascal's constants.

UV-vis spectra determinations were recorded with a Shimadzu $2600 / 2700$ spectrophotometer. This instrument was also used to collect the diffuse reflectance spectra, employing $\mathrm{MgO}$ as a standard. Fluorescence spectra were obtained using a Shimadzu (RF6000) luminescence spectrometer equipped with a pulsed xenon lamp.

\subsection{Synthesis}

\subsection{1. $\left(\mathrm{SerH}_{2}\right)_{2}\left[\mathrm{CuCl}_{4}\right] \cdot 1 / 2 \mathrm{H}_{2} \mathrm{O}$ and $\left(\mathrm{SerH}_{2}\right)_{2}\left[\mathrm{CuCl}_{4}\right]$}

Under continuous stirring, $1 \mathrm{mmol}$ of sertraline hydrochloride was dissolved in a mixture of $50 \mathrm{~mL}$ of ethyl acetate and $25 \mathrm{~mL}$ of $96 \%$ ethanol and then the solution was heated to boiling until the solute was entirely dissolved. A solution containing $0.5 \mathrm{mmol}$ of $\mathrm{CuCl}_{2} \cdot 2 \mathrm{H}_{2} \mathrm{O}$ was prepared in $1 \mathrm{~mL}$ of $37 \% \mathrm{HCl}$ and it was slowly drop-wise added to the first solution of sertraline hydrochloride. Then, the resulting solution was boiled for $30 \mathrm{~min}$ to halve the volume. This solution was then separated into two portions: one portion was cooled to room temperature and the other one placed in the refrigerator for a week to favor the formation of single crystals suitable for structural X-ray diffraction work. Crystals grown from both solutions were filtered out and washed with $96 \%$ ethanol. Elemental analysis: (i) hydrated salt $\left(\mathrm{SerH}_{2}\right)_{2}\left[\mathrm{CuCl}_{4}\right]^{\cdot 1 / 2} \mathrm{H}_{2} \mathrm{O}\left(\mathrm{C}_{34} \mathrm{H}_{37} \mathrm{Cl}_{8} \mathrm{Cu} \mathrm{N}_{2} \mathrm{O}_{0.5}\right)$. Calculated: $49.2 \% \mathrm{C}$, $3.4 \% \mathrm{~N}, 4.5 \% \mathrm{H}$; Found: $49.4 \% \mathrm{C}, 3.6 \% \mathrm{~N}, 4.6 \% \mathrm{H}$ (ii) Un-hydrate salt $\left(\mathrm{SerH}_{2}\right)_{2}\left[\mathrm{CuCl}_{4}\right]\left(\mathrm{C}_{34} \mathrm{H}_{36} \mathrm{Cl}_{8} \mathrm{Cu} \mathrm{N}_{2}\right)$. Calculated: $49.7 \% \mathrm{C}, 3.4 \% \mathrm{~N}, 4.4 \%$ H. Found: $50.0 \% \mathrm{C}, 3.6 \% \mathrm{~N}, 4.3 \% \mathrm{H}$. Thermogravimetric analysis (oxygen atmosphere, $50 \mathrm{~mL} / \mathrm{min}$ ): (i) hydrate salt: the water loss finishes at relatively high temperatures, (endothermic peak, $189^{\circ} \mathrm{C}$ ) and the water release involved a percentage of mass loss of $1.2 \%$ in concordance with the calculated one $(\Delta \omega$ calc $=1.1 \%)$. After dehydration, the compound degraded in a series of two consecutive TG steps observed up to $200{ }^{\circ} \mathrm{C}$. Weight constancy is attained $750{ }^{\circ} \mathrm{C}$ and the weight of the remaining solid residue was of $9.7 \%$, in good agreement with the expected value of $9.6 \%$. The presence of $\mathrm{CuO}$ in the residue was 
confirmed by FTIR spectroscopy.(ii) Un-hydrate salt: similar behavior except for the water content. The decomposition of the sample started at $170{ }^{\circ} \mathrm{C}$. The residue at $800{ }^{\circ} \mathrm{C}$ has also been identified as $\mathrm{CuO}$ with a mass loss of $9.9 \%(\Delta \omega$ calc $=9.7 \%)$.

In both preparations, the yield of the new compound varied from 70 to $80 \%$. The compounds present solid state stability in air, and both are soluble in dimethylsulfoxide and ethanol. The solid state molecular structures were determined by $\mathrm{X}$-ray diffraction analysis as $\left(\mathrm{SerH}_{2}\right)_{2}\left[\mathrm{CuCl}_{4}\right] \cdot \frac{1}{2} \mathrm{H}_{2} \mathrm{O}\left(\mathrm{C}_{34} \mathrm{H}_{37} \mathrm{Cl}_{8} \mathrm{CuN}_{2} \mathrm{O}_{0.5}\right)$ for the crystals from the refrigerator (hemi-hydrate form, yellow crystals) and as $\left(\mathrm{SerH}_{2}\right)_{2}\left[\mathrm{CuCl}_{4}\right]\left(\mathrm{C}_{34} \mathrm{H}_{36} \mathrm{C}_{18} \mathrm{CuN}_{2}\right.$, yellow crystals) for the room temperature crystals (un-hydrate form).

\subsubsection{Single crystal $X$-ray diffraction data}

The measurements were performed on an Oxford Xcalibur Gemini, Eos CCD diffractometer with graphite-monochromated MoKa $(\lambda=0.71073 \AA)$ and $\mathrm{CuKa}(\lambda=1.54178 \AA$ ) radiation for the hydrate and un-hydrate, respectively. X-ray diffraction intensities were collected ( $\omega$ scans with $\vartheta$ and $\kappa$-offsets), integrated and scaled with CrysAlisPro [26] suite of programs. The unit cell parameters were obtained by least-squares refinement (based on the angular settings for all collected reflections with intensities larger than seven times the standard deviation of measurement errors) using CrysAlisPro. Data were corrected empirically for absorption employing the multi-scan method implemented in CrysAlisPro. The structures were solved by direct methods with SHELXS of the SHELX suit of programs [27] and the corresponding molecular models developed by alternated cycles of Fourier methods and full-matrix least-squares refinement with SHELXL of the same package. The hydrogen atoms of all $\mathrm{SerH}_{2}{ }^{+}$molecules were positioned stereo-chemically and refined with the riding model. The methyl H-positions were optimized by treating them as a rigid group which was allowed to rotate during the refinement around the corresponding $\mathrm{N}-\mathrm{C}$ bonds such as to maximize the residual electron density at the calculated positions. One water $\mathrm{H}$-atom of $(\mathrm{SerH})_{2}\left[\mathrm{CuCl}_{4}\right] \cdot \frac{1}{2} \mathrm{H}_{2} \mathrm{O}$ was located in a difference Fourier map and refined at its found position with an isotropic displacement parameter. The other water $\mathrm{H}$-atom could not be located reliably and therefore it was not included in the final molecular model. Crystal data, data collection procedure, structure determination methods and refinement results are summarized in Table 1.

Crystallographic structural data have been deposited at the Cambridge Crystallographic Data Centre (CCDC). Any request to the CCDC for this material should quote the full literature citation and the reference number CCDC $1519924\left[(\mathrm{SerH})_{2}\left[\mathrm{CuCl}_{4}\right] \cdot \frac{1}{2} \mathrm{H}_{2} \mathrm{O}\right]$ and CCDC $1519925\left[(\mathrm{SerH})_{2}\left[\mathrm{CuCl}_{4}\right]\right]$.

\section{3. in vitro biological and pharmacological activities}

\subsubsection{Anti-thyroid activity}

Iodine complexation was assayed following our reported methods, based on Lang's method [17]. Experiments concerning lactoperoxidase from bovine milk (LPO)-inhibition were performed as follows using phosphate buffer ( $\mathrm{pH} 7)$ at $25{ }^{\circ} \mathrm{C}$. The spectroscopic data were collected with a UV/Vis spectrophotometer and the assay of LPO enzyme activity was followed by catalysis of ABTS oxidation monitoring the UV absorption at $411 \mathrm{~nm}$. The enzyme activity, after the complex addition, was expressed as a percentage of that observed in the absence of inhibitors. In a typical experiment, $100 \mathrm{mM}$ ABTS and $30 \mathrm{mM}$ hydrogen peroxide solutions (from a $30 \% \mathrm{w} / \mathrm{w}$ solution) were freshly prepared in deionized water. A solution of the lactoperoxidase enzyme $\left(0.15-0.25\right.$ unit $\left.\mathrm{mL}^{-1}\right)$ was prepared in cold deionized water and used immediately for the assay. In a $1 \mathrm{~mL}$ reaction mixture, the final concentrations were $12.9 \mathrm{nM} \mathrm{LPO}, 28.7 \mathrm{mM} \mathrm{H}_{2} \mathrm{O}_{2}, 1.4 \mathrm{mM}$ ABTS, and $1-100 \mathrm{mM}$ of the inhibitor [28].

\subsection{Antioxidant properties}

\subsubsection{Superoxide dismutase assay (SOD)}

The antioxidant properties were assayed following our reported methods [29]. In this method, the system (PMS)/(NADH) produces the superoxide anion radical. The system contains $0.5 \mathrm{~mL}$ of sample, $0.5 \mathrm{~mL}$ of $1.40 \mathrm{mM} \mathrm{NADH}$, and $0.5 \mathrm{~mL}$ of $300 \mu \mathrm{M} \mathrm{NBT}$, in $0.05 \mathrm{M}$ phosphate buffer (pH 7.5). After incubation at $25^{\circ} \mathrm{C}$ for $15 \mathrm{~min}$, the reaction starts by the addition of $0.5 \mathrm{~mL}$ of $120 \mu \mathrm{M}$ PMS. The solutions of the complex were prepared in DMSO before adding the phosphate buffer to obtain the desired final concentrations. The final DMSO to buffer concentration ratio never exceeded 5:100. Then, the reaction mixture was incubated for $5 \mathrm{~min}$ at $25^{\circ} \mathrm{C}$. For comparative purposes sertraline was tested under the same experimental conditions. The results were determined by monitoring the absorbance at $560 \mathrm{~nm}$. The amount of compound that produced a $50 \%$ inhibition of NBT reduction was obtained from a plot of percentage of inhibition versus compound concentration. Kinetic constant value $(k)$, which is independent of both detector concentration and nature, was calculated according to: $k_{\mathrm{McCF}}=k$ detector $\mathrm{x}$ [detector] $/ \mathrm{IC}_{50}$ (compound), where $k_{\mathrm{NBT}}(\mathrm{pH} 7.8$ ) $=5.94 \times 10^{4} \mathrm{~mol}^{-1} \mathrm{~L} \mathrm{~s}^{-1}$ and [detector] $=$ detector concentration.

\subsubsection{1,1-Diphenyl-2-picrylhydrazyl assay}

The antiradical activity of the compounds was measured in triplicate as follow: methanolic solution of DPPH $\cdot(4 \mathrm{~mL}, 40 \mathrm{ppm})$ was added to $1 \mathrm{~mL}$ of the antioxidant solutions in $0.1 \mathrm{M}$ Tris- $\mathrm{HCl}$ buffer (pH 7.1) at $25^{\circ} \mathrm{C}$, giving a final concentration of $10 \mu \mathrm{M}$. After $60 \mathrm{~min}$ of the reaction in the dark, the absorbance at $517 \mathrm{~nm}$ was measured and compared with the absorbance of the control prepared in a similar way without the addition of the compounds (this value was assigned arbitrarily as $100 \%)$.

\subsection{Scavenging of the hydroxyl radical}

Hydroxyl radicals were generated by the ascorbate-iron $-\mathrm{H}_{2} \mathrm{O}_{2}$ system. Briefly, the reaction mixture contained $3.75 \mathrm{mM}$ 2-deoxyribose, $2.0 \mathrm{mM} \mathrm{H}_{2} \mathrm{O}_{2}, 100 \mu \mathrm{M} \mathrm{FeCl}_{3}$, and $100 \mu \mathrm{M}$ EDTA with or without the tested compounds in $20 \mathrm{mM} \mathrm{KH}_{2} \mathrm{PO}_{4}-\mathrm{KOH}$ buffer, $\mathrm{pH}$ 7.4. The reaction was triggered by the addition of $100 \mu \mathrm{M}$ ascorbate and the mixture was incubated at $37^{\circ} \mathrm{C}$ for $30 \mathrm{~min}$. Solutions of $\mathrm{FeCl}_{3}$, ascorbate, and $\mathrm{H}_{2} \mathrm{O}_{2}$ were made up in deaerated water immediately before use. The extent of deoxyribose degradation by hydroxyl radical was measured with the thiobarbituric acid method [12].

\subsection{Peroxidase mimetic activity}

The assay was performed according to the procedure published by Feng et al. [30]. Sertraline and the copper complex were dissolved in DMSO. The bromination reaction activity experiments were performed at $25 \pm 0.5{ }^{\circ} \mathrm{C}$ and $\mathrm{pH} 5.8$ (buffer solution of $\mathrm{NaH}_{2} \mathrm{PO}_{4}-\mathrm{Na}_{2} \mathrm{HPO}_{4}$ ). Reactions were initiated with the presence of phenol red solution $(20 \mu \mathrm{M})$, an aliquot of $30 \% \mathrm{H}_{2} \mathrm{O}_{2}, \mathrm{KBr} 2 \mathrm{M}$ and $7.38 \mu \mathrm{M}$ of the copper complex. The expected spectral data should optimally show the gradual disappearance of the peak at $443 \mathrm{~nm}$ due to the loss of phenol red and an increase in the absorbance of the peak at $592 \mathrm{~nm}$ due to the formation of the bromophenol blue product. The spectra were recorded at $1 \mathrm{~min}$ intervals. The first-order character of the reaction is demonstrated by the linearity of plot of $\ln \left([A] /\left[A_{0}\right]\right) v$ s. time, where $A$ and $A_{0}$ are the absorbances at $592 \mathrm{~nm}$, measured at times $t$ and $t=0$, respectively. The rate constants derived from the pseudo-first order plot on the concentrations vary linearly in the experimental conditions.

\subsection{Antimicrobial assays}

The antibacterial and antifungal profiles of the $\left(\mathrm{SerH}_{2}\right)_{2}\left[\mathrm{CuCl}_{4}\right]$ have been studied against bacterial and fungal strains by the agar 
Table 1

Crystal data and structure refinement results for the $\left(\mathrm{SerH}_{2}\right)_{2}\left[\mathrm{CuCl}_{4}\right]$ salts.

\begin{tabular}{|c|c|c|}
\hline & Hydrate & Un-hydrate \\
\hline Empirical formula & $\mathrm{C}_{34} \mathrm{H}_{37} \mathrm{Cl}_{8} \mathrm{Cu} \mathrm{N} \mathrm{N}_{2} \mathrm{O}_{0.5}$ & $\mathrm{C}_{34} \mathrm{H}_{36} \mathrm{Cl}_{8} \mathrm{Cu} \mathrm{N} \mathrm{N}_{2}$ \\
\hline Formula weight & 828.79 & 819.79 \\
\hline Temperature (K) & $297(2)$ & $297(2)$ \\
\hline Wavelength (Å) & 0.71073 & 1.54184 \\
\hline Crystal system & Monoclinic & Monoclinic \\
\hline Space group & $P 2_{1}$ & $P 2_{1}$ \\
\hline \multicolumn{3}{|l|}{ Unit cell dimensions } \\
\hline a $(\AA)$ & $8.0807(2)$ & $13.8727(6)$ \\
\hline $\mathrm{b}(\AA)$ & $36.2781(8)$ & $7.5090(3)$ \\
\hline c $(\AA)$ & $12.6576(3)$ & $18.618(1)$ \\
\hline$\beta\left({ }^{\circ}\right)$ & $95.665(2)$ & $104.563(6)$ \\
\hline Volume $\left(\AA^{3}\right)$ & $3692.5(2)$ & $1877.1(2)$ \\
\hline $\mathrm{Z}$, density (calcu., $\mathrm{Mg} / \mathrm{m}^{3}$ ) & 4, 1.491 & $2,1.450$ \\
\hline Absorption coefficient $\left(\mathrm{mm}^{-1}\right)$ & 1.200 & 6.267 \\
\hline $\mathrm{F}(000)$ & 1696 & 838 \\
\hline Crystal shape/color & Plate/yellow & Plate/yellow \\
\hline Crystal size $\left(\mathrm{mm}^{3}\right)$ & $0.375 \times 0.176 \times 0.051$ & $0.237 \times 0.083 \times 0.037$ \\
\hline$\vartheta$-range $\left({ }^{\circ}\right)$ for data collection & 2.868 to 27.000 & 3.291 to 72.396 \\
\hline Index ranges & $-9 \leq \mathrm{h} \leq 10,-43 \leq \mathrm{k} \leq 45,-16 \leq 1 \leq 16$ & $-17 \leq \mathrm{h} \leq 16,-9 \leq \mathrm{k} \leq 5,-22 \leq 1 \leq 22$ \\
\hline Reflections collected & 22,045 & 8261 \\
\hline Independent reflections & $13,434[R$ (int) $=0.0292]$ & $4754[R$ (int) $=0.0612]$ \\
\hline Observed reflections $[I>2 \sigma(\mathrm{I})]$ & 11,104 & 3244 \\
\hline Completeness (\%) to $\vartheta=25.24^{\circ}$ & 99.8 & 99.9 \\
\hline Absorption correction & Semi-empirical from equivalents & Semi-empirical from equivalents \\
\hline Refinement method & Full-matrix least-squares on $\mathrm{F}^{2}$ & Full-matrix least-squares on $\mathrm{F}^{2}$ \\
\hline Data/restraints/parameters & $13,434 / 2 / 828$ & $4754 / 1 / 408$ \\
\hline Goodness-of-fit on $\mathrm{F}^{2}$ & 1.021 & 1.025 \\
\hline Final $R$ indices $^{\mathrm{a}}[I>2 \sigma(\mathrm{I})]$ & $R_{1}=0.0392, \mathrm{w} R_{2}=0.0746$ & $R_{1}=0.0719, \mathrm{w} R_{2}=0.1714$ \\
\hline $\mathrm{R}$ indices (all data) & $R_{1}=0.0536, \mathrm{w} R_{2}=0.0808$ & $R_{1}=0.1047, \mathrm{w} R_{2}=0.1996$ \\
\hline Absolute structure parameter & $-0.003(7)$ & $0.03(4)$ \\
\hline Larg. diff. peak and hole $\left(\mathrm{e} \cdot \AA^{-3}\right)$ & 0.317 and -0.303 & 1.272 and -0.456 \\
\hline
\end{tabular}

${ }^{\mathrm{a}} R_{1}=\Sigma|| F_{o}|-| F_{c}|| / \Sigma\left|F_{o}\right|, \mathrm{w} R_{2}=\left[\Sigma w\left(\left|F_{o}\right|^{2}-\left|F_{c}\right|^{2}\right)^{2} / \Sigma w\left(\left|F_{o}\right|^{2}\right)^{2}\right]^{1 / 2}$.

dilution method. Control strains included five bacterial strains: Escherichia coli ATCC 35218, Pseudomonas aeruginosa ATCC 27853, Staphylococcus aureus ATCC 25923, Staphylococcus epidermidis ATCC 1263 and Enterococcus faecalis ATCC 29212 and seven strains of Candida namely: Candida parapsilosis ATCC 22019, Candida albicans ATCC 10231, and clinical isolates of Candida tropicalis, Candida krusei, Candida glabrata, Candida parapsilosis and Candida albicans. Mueller Hinton Broth (MHB) or Mueller Hinton Agar (MHA) has been used for the cultivation/assay medium for all strains. The inocula of bacterial and fungal strains were prepared from $18 \mathrm{~h}$-old broth cultures. A McFarland 0.5 suspension was prepared for each isolate $\left(\sim 10^{8}\right.$ colony forming units (CFU) per $\mathrm{mL}, \mathrm{CFU} \mathrm{mL}{ }^{-1}$ ). The fungal suspension $\left(\sim 10^{8} \mathrm{CFU} \mathrm{mL}^{-1}\right)$ was directly inoculated onto the agar surface, whereas the bacterial suspension was 1:10 diluted prior to inoculation $\left(\sim 10^{7} \mathrm{CFU} \mathrm{mL}{ }^{-1}\right)$. The minimum inhibitory concentration (MIC) was determined by the agar dilution method. The compounds were dissolved in $50 \%$ aqueous dimethylsulfoxide (DMSO) solution to a final concentration of $15 \mathrm{mg} \mathrm{mL}^{-1}$. Serial two-fold water dilutions were prepared from the stock solution of the antimicrobial agents to give concentrations ranging from 14.65 to $15,000 \mu \mathrm{gL}^{-1}$. All solutions were sterilized by filtration before use. Then, $0.5 \mathrm{~mL}$ of each dilution of antimicrobial solution were added to $4.5 \mathrm{~mL}$ of melted MHA and poured into a square $(45 \times 15 \mathrm{~mm})$ plate. The final concentrations ranging in the MHA were from 1.46 to $1500 \mu \mathrm{g} \mathrm{mL}{ }^{-1}$. An agar plate without antibacterial agent was established as a sterility and organism growth controls. The plates were prepared and used on the same day. After cooling and drying, the plates were inoculated with each microbial suspension. The inoculum of $2 \mu \mathrm{L}$ of the germ suspensions were streaked onto the plates and incubated aerobically at $37^{\circ}$ for $24 \mathrm{~h}$ and $48 \mathrm{~h}$ for bacteria and fungi, respectively. Each MIC experiment was repeated three times. Inhibition of microbial growth in the plates containing tested solutions was judged by comparison with growth in control plates. The MIC was defined as the lowest dilution of the complex that inhibited the visible growth of the tested organism. A single colony or a faint haze caused by the inoculum was considered to be no growth [10].

\subsection{In vivo pharmacological screening}

The prepared compound was evaluated for their in vivo antidepressant and analgesic activities by the Forced Swimming test (FST) and the hot plate method in Wistar rats, respectively.

\subsection{Animals}

Experiments were carried out on male Wistar rats weighing 170-290 g. The animals were maintained on a 12 hour light (08:00-20:00 h)-12 hour dark cycle, with free access to food and water, except during testing. Under these conditions, abundant evidence seems to rule out possible interference with experimental data [[31].].

Rats were housed in groups of four, in individual polyethylene cages $(55 \times 38 \times 30 \mathrm{~cm})$. Their weights were recorded at the beginning and end of each experiment. Animals were used only in one experiment.

All studies described were conducted in accordance with the Guide for Care and Use of Laboratory Animals provided by the National Institutes of Health, USA and AVMA Guidelines for the Euthanasia of Animals, $2013 \mathrm{Ed}$. The experiments were performed after approval of the protocol by the Ethics Committee for the care and use of Laboratory Animals of the Universidad Nacional de La Rioja, Argentina.

\subsection{Antidepressant activity}

\subsubsection{Drugs and treatment}

For $\left(\mathrm{SerH}_{2}\right)_{2}\left[\mathrm{CuCl}_{4}\right]$ the experimental doses of 13.30 and $26.6 \mathrm{mg} /$ $\mathrm{kg}$ and a therapeutic dose of $10.00 \mathrm{mg} / \mathrm{kg}$ and a higher dose of $20.0 \mathrm{mg} / \mathrm{kg}$ of sertraline have been selected. The doses of the copper 
salts were proportionally equivalent to those of sertraline. Higher doses have also been selected to evaluate its dose-response activity.

Rats were treated with the saline solution (rats control) or $\mathrm{CuCl}_{2}$, sertraline hydrochloride and $\left(\mathrm{SerH}_{2}\right)_{2}\left[\mathrm{CuCl}_{4}\right]$ once a day and all solutions were administered by oral route in a constant volume of $10 \mathrm{~mL} / \mathrm{kg}$ body weight. The rats were randomly distributed into five groups which were subjected to the following treatments: Group 1: saline (control group), Group 2: $\mathrm{CuCl}_{2}(2.70 \mathrm{mg} / \mathrm{kg})$, Group 3: $\mathrm{CuCl}_{2}(5.40 \mathrm{mg} / \mathrm{kg})$, Group 4. sertraline hydrochloride $(10.0 \mathrm{mg} / \mathrm{kg})$, Group 5 . sertraline hydrochloride $(20.0 \mathrm{mg} / \mathrm{kg})$, Group 6: $\left(\mathrm{SerH}_{2}\right)_{2}\left[\mathrm{CuCl}_{4}\right](13.30 \mathrm{mg} / \mathrm{kg})$ and Group 7: $\left(\mathrm{SerH}_{2}\right)_{2}\left[\mathrm{CuCl}_{4}\right](26.6 \mathrm{mg} / \mathrm{kg})$. Saline solution and compounds were administered orally by gavage (p.o.) for 14 days. Statistical analysis was carried out by one-way ANOVA followed by Bonferroni's test.

\subsection{Forced swimming test (FST)}

The forced swimming test (FST) is a well-accepted procedure to quantify the antidepressant-like action of drugs [32] and to assay through rat treatments the antidepressant efficacy in humans [33]. Stress is a well-known risk factor in the development of depression. The FST employs forced swimming stimuli as stressor to generate a behavior characterized by increased immobility time.

Swimming sessions were conducted by placing rats in individual Plexiglas cylinders $(46 \mathrm{~cm}$ tall $\times 20 \mathrm{~cm}$ in diameter), filled with water $\left(23-25^{\circ} \mathrm{C}\right)$ up to $30 \mathrm{~cm}$ from bottom. All swimming sessions were carried out between 12:00 and 18:00 $\mathrm{h}$.

In the protocol, two sessions were conducted: an initial 15 min pretest on day 1 followed by a 5 min test on day 15. Drug treatments began on day 1 after the pre-test session and it was administered from day 1 to 14 [34]. At the end of both swimming sessions, rats were removed from the cylinders, dried with towels, placed in heated cages for $15 \mathrm{~min}$, allowed to rest and recover, and then returned to their home cages. The cylinders were emptied and cleaned between rat tests. Each animal was assigned randomly to a treatment, and was only employed for one pretest/test session.

\subsection{Analgesic activity-hot plate test}

The hot plate consisted of an electrically heated surface (Socrel DS35, Ugo Basile, Comerio, VA, Italy) kept at a constant temperature of $54 \pm 0.8^{\circ} \mathrm{C}$. In the test, the rats were kept inside a circular transparent plastic cage on the hot plate. The time taken for the rats to respond to the thermal stimulus (licking paws or jumping surface) was recorded as the response latency (in second). If the animals did not respond within $45 \mathrm{~s}$ (cut-off time), they were removed from the plate to avoid tissue damage [35]. Animals were distributed in 4 groups: Group 1: saline solution $(0.4 \% \mathrm{NaCl})$ (control), Group 2: sertraline $\left(\mathrm{SerH}_{2} \mathrm{Cl}\right)(10 \mathrm{mg} /$ $\mathrm{Kg})$, Group 3: $\mathrm{CuCl}_{2}(2.7 \mathrm{mg} / \mathrm{Kg})$ and Group 4: $\left(\mathrm{SerH}_{2}\right)_{2}\left[\mathrm{CuCl}_{4}\right]$ $(13.30 \mathrm{mg} / \mathrm{kg})$. Saline solution and compounds were administered orally by gavage (p.o.) for 14 days. The antinociceptive activity of $\left(\mathrm{SerH}_{2}\right)_{2}\left[\mathrm{CuCl}_{4}\right], \mathrm{CuCl}_{2}$ and sertraline, after acute and chronic administration (for 14 days), was evaluated using hot plate method. Statistical analysis was carried out by one-way ANOVA followed by Dunnett's test. In acute experiments, rats were administered $60 \mathrm{~min}$ prior to hot plate test or open field test and in chronic experiments $24 \mathrm{~h}$ after the last dose administration.

\subsection{Behavioral scoring}

For behavioral sampling, rats were rated at $5 \mathrm{~s}$ intervals throughout the duration of the forced swimming session. At each $5 \mathrm{~s}$ interval, the predominant behavior was assigned to one of three categories: (1) immobility: floating in the water without struggling, and making only those movements necessary to keep the head above the water; (2) swimming: making active swimming motions, more than necessary to merely keep the head above water (i.e., moving around in the cylinder); and (3) climbing: making active movements with forepaws in and out of the water, usually directed against the walls. Scores for each behavior were expressed as total behavioral counts per 5-min session [32].

\subsection{Open field test}

This test was carried out to determine whether different treatments that were effective in the hot plate test or forced swimming test had non-specific effects because the locomotor activity may influence immobility in the forced swim test [36] or in the latency response in the hot plate test [37].

The apparatus used consisted of a black, square open field $(60 \mathrm{~cm}$ by $60 \mathrm{~cm}$ ) with the floor divided in squares $(15 \times 15 \mathrm{~cm})$ by means of white lines. The open field was placed in a quiet room only illuminated with a $75 \mathrm{~W}$ electric bulb hung $75 \mathrm{~cm}$ above it. Testing was performed between 14:00 and 17:00 $\mathrm{h}$.

Each animal was placed in the centre of the open-field arena and the locomotor activity was expressed as the number of floor units the animal entered with all of its limbs over a period of $5 \mathrm{~min}$. (ambulatory counts). After each animal was removed, the open field was carefully cleaned with a damp cloth.

The locomotor activity in rats was evaluated $10 \mathrm{~min}$ previously exposed to the forced swimming test or hot plate test. The behavior was scored by an observer who was unaware of the experimental procedures previously performed on the animals and the results were expressed as mean \pm S.E.M.

\subsection{Albumin interaction}

Bovine serum albumin (BSA) was dissolved in $0.1 \mathrm{M}$ Tris-HCl buffer $(\mathrm{pH} 7.4)$ to attain a final concentration of $6 \mu \mathrm{M}$. Sertralonium tetrachlorocuprate(II) solution was added drop-wise to the above $6 \mu \mathrm{M}$ BSA preparation to ensure the formation of a homogeneous solution and to obtain the desired concentration of $0-100 \mu \mathrm{M}$. Adequate solubility was reached under these experimental conditions and the compounds did not showed significant fluorescence that could interfere with the measurements. For each sample and concentration, three independent replicates were performed at $25{ }^{\circ} \mathrm{C}$ and $37^{\circ} \mathrm{C}$. BSA $6 \mu \mathrm{M}$ was titrated by successive additions of complex solutions from 0 to $100 \mu \mathrm{M}$ and the fluorescence intensity was measured (excitation at $280 \mathrm{~nm}$ and emission at $348 \mathrm{~nm}$ ). All the fluorescence quenching data were analyzed according to previous studies performed in the laboratory by applying a traditional mathematical procedure. The fluorescence-quenching mechanism has been analyzed using the Stern-Volmer Eq. (1) $[38,39]$..

$\mathrm{F}^{0} / \mathrm{F}=1+\mathrm{K}_{\mathrm{sv}}[\mathrm{Q}]$

where $\mathrm{F}^{0}$ is the steady-state fluorescence intensity of BSA alone while $\mathrm{F}$ is the observed intensity upon increasing the quencher concentration, $\mathrm{K}_{\mathrm{sv}}$ is the Stern-Volmer quenching constant and [Q] is the quencher concentration. Usually, the curve of $\mathrm{F}^{0} / \mathrm{F} v s$. [Q] is linear if the type of quenching involves a unique process: static or dynamic. Static quenching is due to the complex formation between the fluorophore and the quencher. It can be distinguished from collision effects because generally the $\mathrm{K}_{\mathrm{sv}}$ value is higher than the value of the dynamic quenching constant $\left(\mathrm{K}_{\mathrm{q}}\right.$ ). Considering that $\mathrm{K}_{\mathrm{q}}=\mathrm{K}_{\mathrm{sv}} / \tau_{0}$ (where $\tau_{0}=10^{-8} \mathrm{~s}$ is the average lifetime of the biomolecule without quencher), this constant can be estimated and compared with the maximum diffusion collision quenching rate constant (reference value from the literature) which is $2 \times 10^{-10} \mathrm{M}^{-1} \mathrm{~s}^{-1}[38,39]$. If the $\mathrm{K}_{\mathrm{sv}}$ value is greater, then a mechanism of interaction through the complex formation can be proposed. Otherwise it would be a collisional quenching. If the quenching is static, it is assumed that there are specific binding sites. These binding sites, and their association constants, were estimated using the following mathematical relationship: 
$\left.\log \left[\left(\mathrm{F}^{0}-\mathrm{F}\right) / \mathrm{F}\right)\right]=\log \mathrm{K}_{\mathrm{b}}+\mathrm{n} \log [\mathrm{Q}]$

where $\mathrm{K}_{\mathrm{b}}$ is the binding constant and $n$ is the average number of biding site per protein molecule.

To obtain information about the type of interaction, the thermodynamic parameters were calculated using Van't Hoff equation [38,39]:

$\ln \left(\mathrm{K}_{\mathrm{b} 2} / \mathrm{K}_{\mathrm{b} 1}\right)=-\Delta \mathrm{H}^{0} / \mathrm{R}\left(1 / \mathrm{T}_{2}-1 / \mathrm{T}_{1}\right)$

where $T_{1}$ and $T_{2}$ are the absolute temperatures at which $\mathrm{K}_{\mathrm{b} 1}$ and $\mathrm{K}_{\mathrm{b} 2}$ were determined. The standard free energy change $\left(\Delta \mathrm{G}^{0}\right)$ and the standard free entropy change $\left(\Delta S^{0}\right)$ were evaluated according to the well known thermodynamic relationships:

$\Delta \mathrm{G}^{0}=-\mathrm{RT} \ln \mathrm{K}_{\mathrm{b}}$

$\Delta S^{0}=\left(\Delta H^{0}-\Delta G^{0}\right) / T$,

\section{Results and discussion}

\subsection{Crystallographic structural results}

The crystal asymmetric unit of the un-hydrate hosts a single $\left(\mathrm{SerH}_{2}\right)_{2}\left[\mathrm{CuCl}_{4}\right] \cdot \frac{1}{2} \mathrm{H}_{2} \mathrm{O}$ molecule while the hemi-hydrate contains two different molecules which share a single crystallization water molecule. In what follows, we shall discuss mainly the molecular structure of the

\section{A}

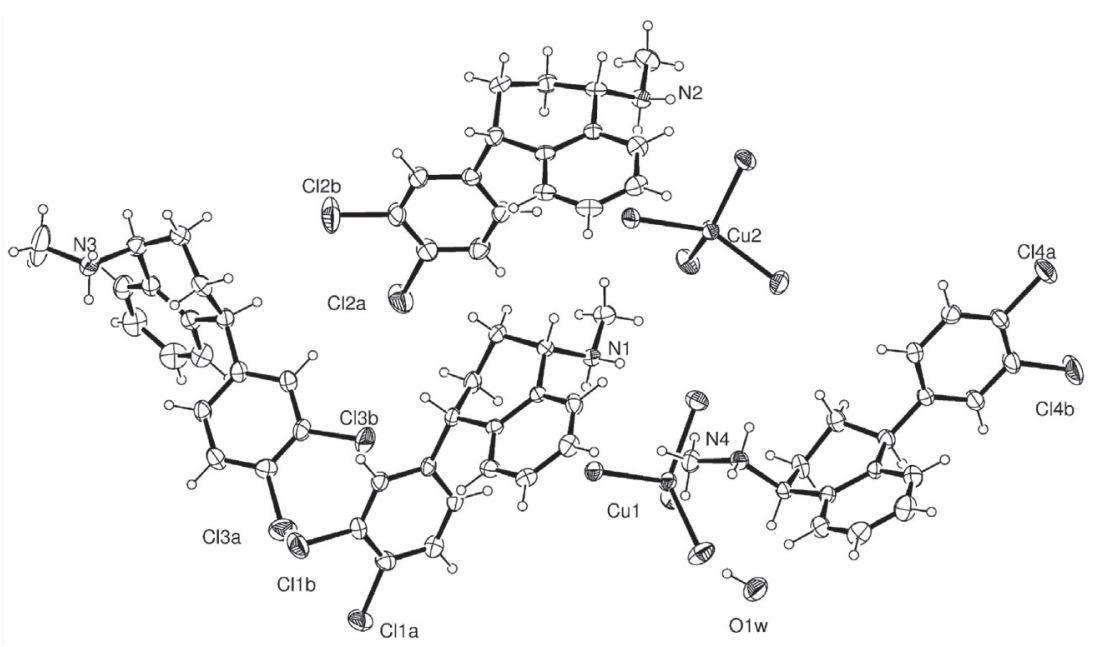

B
Fig. 1 shows an ORTEP [40] drawing of $\left(\mathrm{SerH}_{2}\right)_{2}\left[\mathrm{CuCl}_{4}\right] \cdot \frac{1}{2} \mathrm{H}_{2} \mathrm{O}$ and the corresponding intra-molecular bond distances and angles of this and the un-hydrate salts are respectively given in Tables S1a and S1b. All pharmaceutical sertraline $\left(\mathrm{SerH}_{2}{ }^{+}\right)$molecules in both solid forms are found in the cationic moiety, protonated at its amine group, namely (1S,4S)-4-(3,4-dichlorophenyl)- $N$-methyl-1,2,3,4-tetrahydro naphthalen-1-amine (for short, $\mathrm{SerH}_{2}{ }^{+}$).

Because of extended molecular orbital $\pi$-delocalization the phenyl and dichlorophenyl groups of $\mathrm{SerH}_{2}{ }^{+}$are planar [rms deviation of non$\mathrm{H}$ atoms from the best least-square plane $<0.010 \AA$ for phenyl rings and $<0.031 \AA$ for dichlorophenyl groups]. Phenyl and dichlorophenyl planes, in turn, subtend dihedral angles of $87.9(1)^{\circ}$ (SerH \#1), 81.3(1) ${ }^{\circ}$ (SerH \#2), 68.8(1) $)^{\circ}$ (SerH \#3), and 86.5(1) (SerH \#4).

Intra-molecular bond distances and angles within the $\mathrm{SerH}_{2}{ }^{+}$molecules in both salts agree with each other and with corresponding values reported for the related $\left(\mathrm{SerH}_{2}\right)_{2}\left[\mathrm{ZnCl}_{4}\right]$ salt [11], sertraline hydrochloride polymorphs [41,42], for other $\mathrm{SerH}_{2}{ }^{+}$salts $[43,44]$. and for the sertraline coumarin 3-carboxylate [10].

The four independent $\mathrm{SerH}_{2}{ }^{+}$molecules in $\left(\mathrm{SerH}_{2}\right)_{2}\left[\mathrm{CuCl}_{4}\right]^{-1 / 2} \mathrm{H}_{2} \mathrm{O}$ can be grouped in two sets, (\#1, \#3) and (\#2, \#4), with the molecules in each set having the same boat-like conformation of naphathalene rings. Besides this, the conformations of the $\mathrm{SerH}_{2}{ }^{+}$molecules differ significantly from each other and from the ones of the other related better refined hydrated salt.

Fig. 1. Drawing of (A) $\left(\mathrm{SerH}_{2}\right)_{2}\left[\mathrm{CuCl}_{4}\right] \cdot \frac{1}{2} \mathrm{H}_{2} \mathrm{O}$ and (B) $\left(\mathrm{SerH}_{2}\right)_{2}\left[\mathrm{CuCl}_{4}\right]$ showing the labeling of the non-H atoms and their displacement ellipsoids at the $30 \%$ probability level. For clarity, only a few representative atoms have been identified in the hydrate to show the numbering scheme.
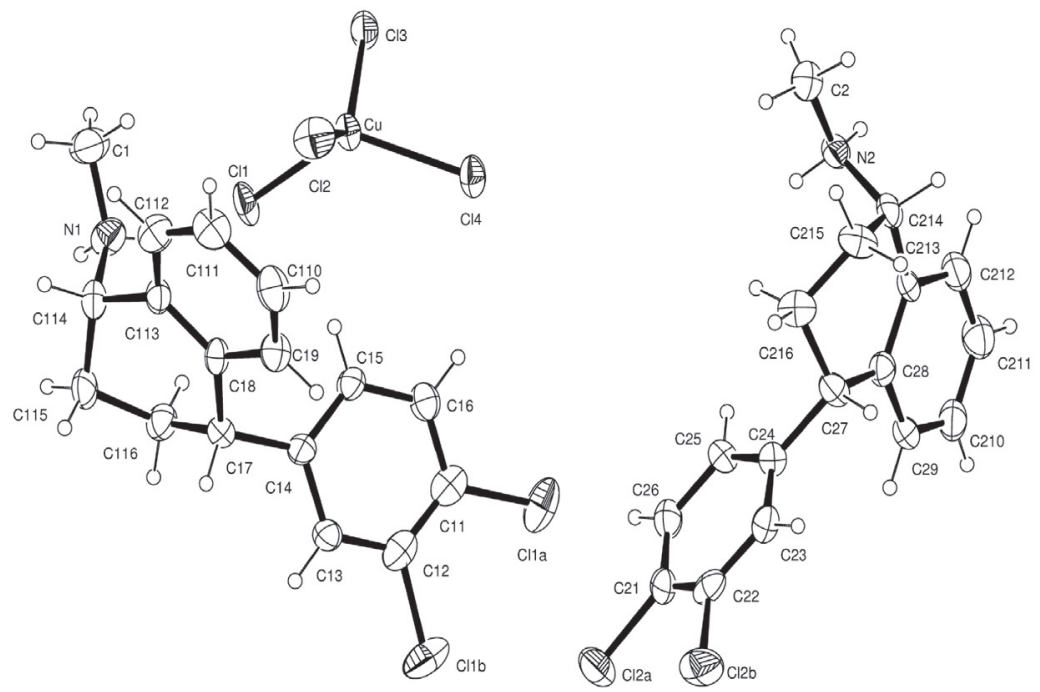
compounds. This can be traced to relatively unhindered rotational freedom of $\mathrm{SerH}_{2}{ }^{+}$around the $\mathrm{C}-\mathrm{C} \sigma$-bond linking the dichlorophenyl and the naphthalene rings and also around the $\mathrm{C}$ (naph) $-\mathrm{N}$ o-bond.

As expected, the mayor differences in bond lengths of $\mathrm{SerH}_{2}{ }^{+}$molecules as compared with neutral sertraline [45], show up as a lengthening of C(naph)-N (of 0.045(8) $\AA$ in average) and in less degree of $\mathrm{N}$ $\mathrm{CH}_{3}$ (average of $0.022(8) \AA$ ) bond distances upon attachment of the proton to the amine groups.

Copper-chloride distances in the $\left[\mathrm{CuCl}_{4}\right]^{2-}$ counter-ions are in the range from 2.204(2) to 2.288(1) $\AA$. Consistent with the tendency of $\mathrm{Cu}$ (II) ion to form square planar complexes, $\left[\mathrm{CuCl}_{4}\right]^{2-}$ shows a highly squashed tetrahedral (along the $C_{2}$ axis) conformation with trans (Cl$\mathrm{Cu}-\mathrm{Cl}$ ) angles in the range from $125.36(6)$ to $141.23(7)^{\circ}$ and cis (Cl-Cu$\mathrm{Cl}$ ) angles in the $93.85(6)-103.90(6)^{\circ}$ range. This contrasts with the $\left[\mathrm{ZnCl}_{4}\right]^{2-}$ counter-ions in the related $(\mathrm{SerH})_{2}\left[\mathrm{ZnCl}_{4}\right]$ salt where the $\mathrm{Zn}$ (II) complex is much closer to a perfect tetrahedron $[\mathrm{Zn}-\mathrm{Cl}$ bond distances in the 2.251(2)-2.282(2) $\AA$ range and $\mathrm{Cl}-\mathrm{Zn}-\mathrm{Cl}$ angles in the range from $105.69(7)$ to $114.76(7)^{\circ}$ ] [11].

The crystalline $\left(\mathrm{SerH}_{2}\right)_{2}\left[\mathrm{CuCl}_{4}\right] \cdot \frac{1}{2} \mathrm{H}_{2} \mathrm{O}$ salt is further stabilized by a complex net of intermolecular $\mathrm{H}$-bonds involving the $\mathrm{SerH}_{2}{ }^{+}$ amide $>\mathrm{NH}_{2}{ }^{+}$as the donor group and as acceptors the water molecule $\left[\mathrm{d}(\mathrm{N} . . . \mathrm{O})=2.798 \AA, \angle(\mathrm{N}-\mathrm{H} . . . \mathrm{OW})=163.9^{\circ}\right]$ and the chlorine atoms of neighboring $\left[\mathrm{CuCl}_{4}\right]^{2-}$ complex ions $[\mathrm{N} . . . \mathrm{Cl}$ distances in the 3.174-3.564 $\AA$ range and $\mathrm{N}-\mathrm{H}$...Cl bond angles in the $119.5-171.9^{\circ}$ range] and also by a $\mathrm{Ow}-\mathrm{H} . . . \mathrm{Cl}$ bond $[\mathrm{d}(\mathrm{Ow} . . \mathrm{Cl})=3.226 \AA$, $\angle(\mathrm{Ow}-\mathrm{H} . . . \mathrm{Cl})=151.5^{\circ}$. The H-bonding structure for both salts is further detailed in the supplementary Tables S6a and S6b.

\subsection{Synthesis and physicochemical characterization}

As mentioned above, different solid state structures were obtained depending on the crystallization temperature. Room temperature favored the formation of the un-hydrate form while the solution preserved at $2-5{ }^{\circ} \mathrm{C}$ led to a hydrate crystal form. Characterization was performed using Infrared, Raman, UV-vis and EPR spectroscopies and magnetic measurements.

Both complexes showed similar FTIR spectra (Fig. S1). The most remarkable changes are produced in the $\mathrm{NH}_{2}{ }^{+}$vibrational modes region (red shift) [11] coming from the hydrogen $\mathrm{N}^{+} \mathrm{H}-\mathrm{X}$ bonding affects (in the hemi-hydrate salt at $2457 \mathrm{~cm}^{-1}\left(\nu_{\text {as }}\right)$ at $2371 \mathrm{~cm}^{-1}\left(\nu_{\mathrm{s}}\right)$ and in the un-hydrate salt at $2450 \mathrm{~cm}^{-1}\left(\nu_{\mathrm{as}}\right)$ and $2368 \mathrm{~cm}^{-1}\left(\nu_{\mathrm{s}}\right)$, respectively). The $\nu(\mathrm{C}-\mathrm{N})$ stretching mode appears at $1029 \mathrm{~cm}^{-1}$ and the $\mathrm{C}-\mathrm{H}$ in-plane bending frequencies, the $\mathrm{C}-\mathrm{H}$ out-of-plane bending and the skeletal vibrations were observed in the expected ranges [11]. Complementary Raman measurements afforded us to assign to the $\nu(\mathrm{C}-\mathrm{Cl})$ stretching mode the peaks found at $481 \mathrm{~cm}^{-1}$ (FTIR) and $483 \mathrm{~cm}^{-1}$ (Raman) and assign two of the expected $\mathrm{Cu}-\mathrm{Cl}$ modes the Raman lines located at 306 and $240 \mathrm{~cm}^{-1}$ (Fig. S2) together with the positive assignment of the absorption of the bending water mode in the hydrate form $\left(1620 \mathrm{~cm}^{-1}\right.$ in the FTIR spectrum) which became barely visible in Raman spectrum. For both complexes, reflectance spectra showed the expected d-d band transition of $\left[\mathrm{CuCl}_{4}\right]^{2-}$ ion $(>850 \mathrm{~nm}$, ${ }^{2} \mathrm{~B}_{2} \rightarrow{ }^{2} \mathrm{~A}_{1}$ transition) and the typical three bands corresponding to charge-transfer transitions located at 401, 282 and $234 \mathrm{~nm}$ (Fig. S3A) $[23,46]$.

The X- and Q-band electron paramagnetic resonance (EPR) spectrum of $\left(\mathrm{SerH}_{2}\right)_{2}\left[\mathrm{CuCl}_{4}\right] .1 / 2 \mathrm{H}_{2} \mathrm{O}$ is shown in Fig. 2. No hyperfine structure or further splitting of the signals was observed [23]. The g-tensor parameters $\left(\mathrm{g}_{\|}=\mathrm{g}_{\mathrm{z}}=2.410\right.$ and $\left.\mathrm{g}_{\mathrm{x}}=\mathrm{g}_{\mathrm{y}}=g_{\perp}=2.120, \mathrm{~g}_{\text {iso }}=2.217\right)$ (Fig. 2C) were resolved with g-values in concordance with the presence of tetrachlorocuprate after the Jahn-Teller dynamic effect has been stabilized.

To study the magnetic behavior of the hydrate sample, the EPR (Xband) spectrum in the range $290-5 \mathrm{~K}$ was measured. The room temperature EPR signal showed a line-shape typical of isotropic ligand field (Fig. 2A). However, as the temperature decreases, the EPR line narrows
(A)

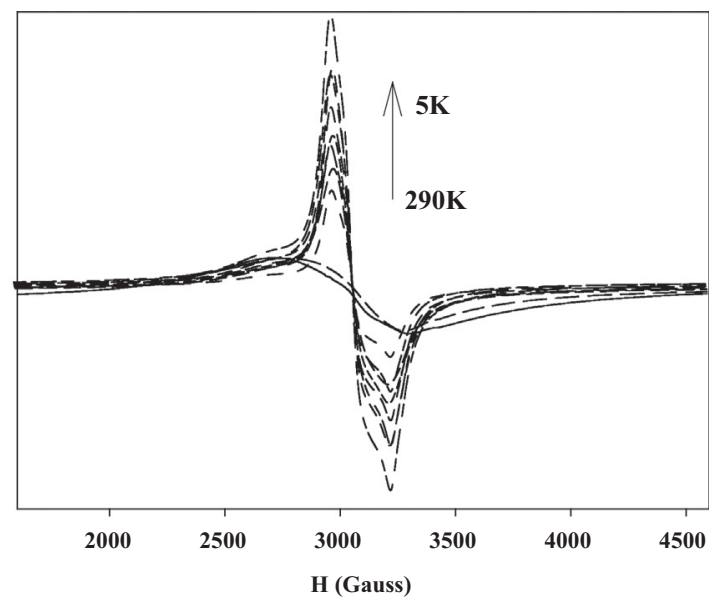

(B)

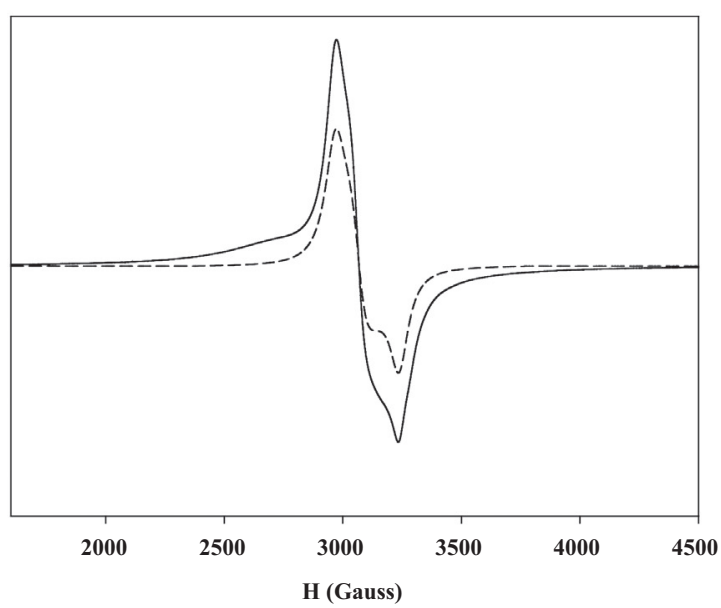

(C)

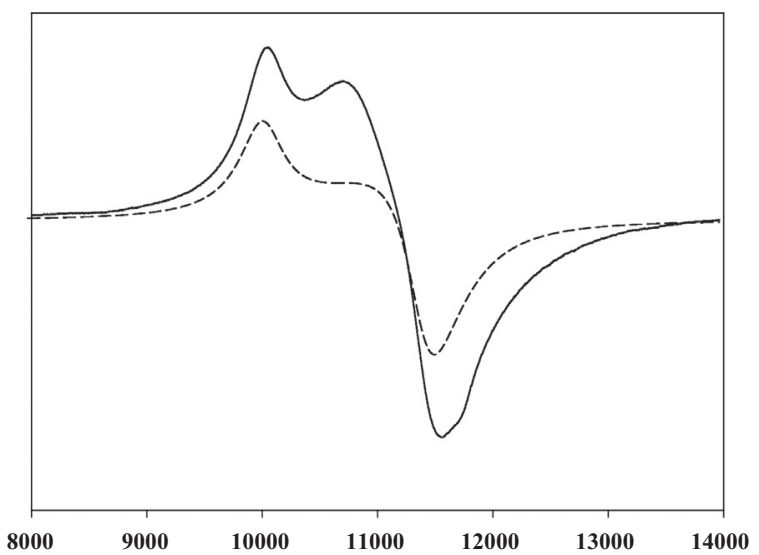

Fig. 2. (A) Temperature dependence of the electron paramagnetic resonance (EPR) spectrum measured at X-band of $\left(\mathrm{SerH}_{2}\right)_{2}\left[\mathrm{CuCl}_{4}\right]^{1 / 1} / 2 \mathrm{H}_{2} \mathrm{O}$ complex from $290 \mathrm{~K}$ to $5 \mathrm{~K}$. (B) Experimental (solid line) and calculated (dashed line) powder electron paramagnetic resonance (EPR) spectrum of the $\left(\mathrm{SerH}_{2}\right)_{2}\left[\mathrm{CuCl}_{4}\right] \cdot \frac{1}{2} \mathrm{H}_{2} \mathrm{O}$ complex measured at X-band $(290 \mathrm{~K}, 9.39 \mathrm{GHz})$

(C) Experimental (solid line) and calculated (dashed line) powder electron paramagnetic

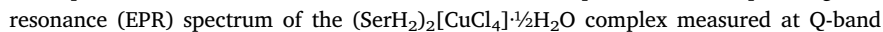
(290 K, $33.9 \mathrm{GHz})$.

and, as a result, the peak intensity increases (Fig. 2B, X-band, 10K). This change in the EPR spectra at low temperature suggests a decrease in the strength of the Jahn-Teller effect. The g-tensor parameters (obtained from a simulation of this EPR spectrum) were in accord with a rhombic- 


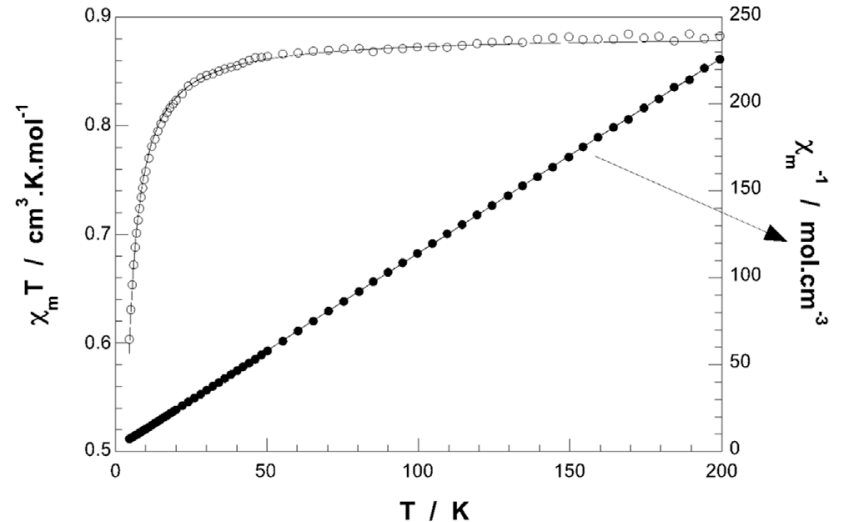

Fig. 3. Magnetic susceptibility of $\left(\mathrm{SerH}_{2}\right)_{2}\left[\mathrm{CuCl}_{4}\right] \cdot \frac{1}{2} \mathrm{H}_{2} \mathrm{O}$ in the temperature range from 5 to $290 \mathrm{~K}$.

like type of signal, namely $g_{z}=2.265, g_{x}=2.075, g_{y}=2.190$ $\left(g_{\text {iso }}=2.176\right)$. To understand the changes, variable-temperature magnetic susceptibility measurements were carried out in the 5-300 K temperature range on a powdered sample of the complex. The thermal variation of the inverse of the magnetic molar susceptibility $\left(\chi_{\mathrm{m}}{ }^{-1}\right)$ and the $\chi_{\mathrm{m}} \mathrm{T}$ product $\left(\chi_{\mathrm{m}} T=\left(\mu_{\mathrm{eff}}\right)^{2} / 8\right)$ are shown in Fig. 3. It can be appreciated that the $\chi_{\mathrm{m}} \mathrm{T}$ magnitude remains practically constant down to $20 \mathrm{~K}$, temperature below which the value of the effective magnetic moment rapidly drops to zero. At room temperature, the $\chi_{\mathrm{m}} \mathrm{T}$ value is $0.885 \mathrm{~cm}^{3} \cdot \mathrm{K}^{\mathrm{mol}}{ }^{-1}$ which are close to the expected value for two uncoupled copper (II) ions with $g=2.18$, in agreement with the EPR results. On the other hand, the Curie-Weiss law

$\chi_{\mathrm{m}}=\mathrm{C}_{\mathrm{m}} /(\mathrm{T}+\theta)$

describes the whole measured temperature range. The calculated values of $C_{m}$ and the Weiss temperature $(\theta)$ are $0.89 \mathrm{~cm}^{3} \cdot \mathrm{K}^{\mathrm{mol}}{ }^{-1}$ and $1.7 \mathrm{~K}$, respectively. This latter temperature is indicative of weak antiferromagnetic super-exchange coupling between the unpaired electrons on neighboring $\left[\mathrm{CuCl}_{4}\right]^{2-}$ ions in the lattice. A more complete description of the observed magnetic behavior can be obtained using the Bleaney-Bowers equation for copper dimers [47], derived from the Heisenberg spin Hamiltonian $\left(H=-2 J S_{1} S_{2}\right)$ for two coupled $S=1 / 2$ ions:

$\chi_{\mathrm{m}}=\left(2 \mathrm{Ng}^{2} \beta^{2} / \mathrm{kT}\right)[3+\exp \cdot(-2 \mathrm{~J} / \mathrm{kT})]^{-1}$

where $\mathrm{N}$ is the Avogadro's number, $\beta$ the Bohr magneton and $\mathrm{k}$ the Boltzmann constant. From the best least-squares fit of Eq. (2) (solid line in Fig. 3) to the susceptibility data, there results an exchange parameter $\mathrm{J} / \mathrm{k}=-2.5 \mathrm{~K}$ and a gyromagnetic g-value of 2.17 , being the reliability R-factor (defined as $\mathrm{R}=\Sigma\left[\chi_{\mathrm{m}} \mathrm{T}^{\exp }-\chi_{\mathrm{m}} \mathrm{T}^{\mathrm{cal}}\right]^{2} / \Sigma\left[\chi_{\mathrm{m}} \mathrm{T}^{\text {exp }}\right]^{2}$ ), equal to $1 \cdot 1 \mathrm{e}^{-5}$. The good agreement between experimental and calculated data confirms the predominance of dimeric super-exchange interactions between neighboring $\left[\mathrm{CuCl}_{4}\right]^{2-}$ ions in the lattice, even if extensive exchange must be operative as indicated by the collapse of the hyperfine structure. The observed smallness of the J-value is due to weak super-exchange paths linking neighboring $\mathrm{Cu}(\mathrm{II})$ ions. In fact, these paths involve long intermolecular $\mathrm{CuCl}$...ClCu and $\mathrm{Cu}$...ClCu distances in the lattice [larger than 4.01 and $4.74 \AA$, respectively] and also unfavorably oriented magnetic molecular orbitals.

The un-hydrate form does not present any outstanding characteristics beyond that published in the literature.

\subsection{Solution characterization and stability}

Because of the similarity of the two compounds, solution characterization, biological, and pharmacological studies were performed only on $\left(\mathrm{SerH}_{2}\right)_{2}\left[\mathrm{CuCl}_{4}\right]$ complex. Conductivity measurement of $1 \mathrm{mM}$ solution of the complex in DMSO was carried out at $25^{\circ} \mathrm{C}$. The molar conductivity of the solution remains constant $\left(\Lambda_{\mathrm{M}}=62 \Omega^{-1} \cdot \mathrm{cm}^{2} \cdot \mathrm{mol}^{-1}\right.$ ) from 1 to $2 \mathrm{~h}$. The conductivity value indicates a 1:2 electrolyte nature of the complex and is consistent with those values found for similar, 1:2 metal complexes in DMSO [48]. The new compound is therefore a 1:2 electrolyte and exists as $\mathrm{SerH}_{2}{ }^{+}$and $\left[\mathrm{CuCl}_{4}\right]^{2-}$ ions.

The UV-vis solution spectrum of the complex (DMSO, $0.001 \mathrm{M}$ ) showed three CT transition bands similar to that found in the solid, located at $258 \mathrm{~nm}\left(\varepsilon=567.5 \mathrm{M}^{-1} \cdot \mathrm{cm}^{-1}\right), 340 \mathrm{~nm}\left(930 \mathrm{M}^{-1} \cdot \mathrm{cm}^{-1}\right)$ and $\sim 422 \mathrm{~nm}$ (shoulder) (Fig. S4A) [23]. At lower energy, the spectrum showed a broad band in the $600-1100 \mathrm{~nm}$ range (Fig. S4B). The pattern of the spectra observed is the one expected for tetrachlorocuprate complexes. The stability of this solution was followed by $\mathrm{UV}$-vis spectroscopy. It was found that after $1 \mathrm{~h}$ of solution preparation, there were no significant spectral changes (Fig. S4A), hence indicating together with the conductivity measurements that during the manipulation time for biological assays (15 $\mathrm{min}$ ) the complex remains stable. By EPR spectroscopy this assumption has also been confirmed (Fig. S4B). The spectrum of a DMSO solution of the new compound showed only one resonance line assuming the presence of one monomeric solution species. The simulation predicted that this signal is originated by a $\mathrm{Cu}(\mathrm{II})$-chromophore with the spin Hamiltonian parameters of $\mathrm{g}_{\text {iso }}=2.175$ and the hyperfine coupling constant of $\mathrm{A}_{\text {iso }}=33 \times 10^{-4} \mathrm{~cm}^{-1}$ in agreement with the expected one for $\mathrm{CuCl}_{4}{ }^{-2}$ species [23].

\subsection{In vitro evaluation of potential biological-pharmacological activities}

\subsubsection{Antimicrobial activity}

Considering the relevance that $\mathrm{Cu}(\mathrm{II})$ complexation and the nitrogen-containing heterocyclic compounds have in the pharmacological profile of antimicrobial activities [49], and taking into consideration the involvement of $P$. aeruginosa, E. coli and $S$. aureus in the development of agranulocytosis (rare complication produced by antithyroid drugs) [50], the effect of the here studied compounds on fungal and bacterial strains were also evaluated. The ability of the complex to inhibit the growth of fungal and bacterial strains was investigated employing the minimum inhibitory concentration (MIC) assay (Table 2).

Antibacterial activity can be quantified as follow: significant results when the MIC values are of $100 \mu \mathrm{gL}^{-1}$ or less; moderate activity when the MIC values are in the $100-500 \mu \mathrm{gL}^{-1}$ range; and lack of activity when MIC values are higher than $1000 \mu \mathrm{g} \mathrm{mL}{ }^{-1}$. It can be seen that the complex exhibits strong activity except against $P$. aeruginosa. Since these activities are similar to the ones showed by sertraline alone, we conclude that the antibacterial properties are most likely due the presence of this pharmaceutical in the complex and no relevant synergistic effect was observed related to the presence of copper. However, it can be noted that a probable administration of the complex will not affect the antimicrobial activity of sertraline.

Table 2

Minimum inhibitory concentrations (MICs) of $\mathrm{SerH}_{2} \mathrm{Cl}$ (sertraline), $\mathrm{CuCl}_{2}$ and $\left(\mathrm{SerH}_{2}\right)_{2}\left[\mathrm{CuCl}_{4}\right]$ for bacterial and fungal strains. MIC values in $\mu \mathrm{g} \mathrm{mL}^{-1}$.

\begin{tabular}{llll}
\hline & $\mathrm{SerH}_{2} \mathrm{Cl}$ & $\mathrm{CuCl}_{2} \cdot 2 \mathrm{H}_{2} \mathrm{O}$ & $\left(\mathrm{SerH}_{2}\right)_{2}\left[\mathrm{CuCl}_{4}\right]$ \\
\hline E. coli & 24 & 375 & 48 \\
P. aeruginosa & 750 & 375 & 1500 \\
E. faecalis & 24 & 375 & 24 \\
S. aureus & 24 & 375 & 48 \\
S. ppidermidis & 24 & 375 & 24 \\
C. albicans & 6 & $>1500$ & 12 \\
C. albicans ATCC 10231 & 12 & $>1500$ & 12 \\
C. parapsilosis & 12 & $>1500$ & 6 \\
C. parapsilosis ATCC 22019 & 6 & $>1500$ & 6 \\
C. krusei & 3 & 1500 & 6 \\
C. glabrata & 3 & 1500 & 6 \\
C. tropicalis & 6 & $>1500$ & 6 \\
\hline
\end{tabular}



$\mathrm{H}_{2} \mathrm{O}_{2}$
$\mathbf{I}^{-}$
TPO $\longrightarrow$ TPO- $\mathrm{O}_{\mathrm{o}}$
(Fe(III))
$(\mathrm{Fe}(\mathrm{IV}))$
$\longrightarrow$
Tyrosine-Tg
Tyrosine-Tg $\longrightarrow \begin{gathered}\text { MIT (Monoiodotyrosine-Tg) } \\ \text { DIT (Diiodotyrosine-Tg) }\end{gathered} \longrightarrow \begin{gathered}\text { L-Trioiodothyronine }\left(\mathrm{T}_{3}\right) \\ \text { Thyroxine }\left(\mathrm{T}_{4}\right)\end{gathered}$
Thyroxine $\left(T_{4}\right)$

Scheme. Schematic representation of the formation of Ltriiodothyronine (T3) and thyroxine (T4).
(B)

\subsubsection{Anti-thyroid activity}

It is well known that an uncontrolled overproduction of thyroid hormones is the reason for a disease condition called "hyperthyroidism". In a proposed mechanism of action, first the thyroid peroxidase (TPO) heme-containing glycoprotein leads via endogenous-produced hydrogen peroxide to the generation of an oxidized form of the enzyme (Scheme,(A)). Then, the oxidized form reacts with iodide to form an iodine-intermediate which in turn reacts with specific tyrosine residues in the thyroglobulin ( $\mathrm{Tg}$ ) to form monoiodotyrosine and diiodotyrosine. Finally, successive intra-molecular coupling of MIT and DIT forms triiodothyronine and the coupling of two DIT molecules affords Ltri-iodo-thyronine (T3) and L-tetra-iodothyronine or thyroxine (T4) formation. (Scheme, (B)).

The overproduction of T4 and T3 can be controlled by anti-thyroid drugs which efficiently can act in two ways, namely (i) forming chargetransfer complexes with molecular iodine in the thyroid gland hence avoiding the access of the iodine to the thyroglobulin, or (ii) inhibiting thyroid peroxidase (TPO) and blocking the thyroid hormone synthesis. Based in those possibilities, the ability of the complex to form charge transfer-iodine complex and to inhibit LPO has been evaluated. Due to the fact that sertraline hydrochloride-iodine interaction was previously shown to lead to charge-transfer complex with iodine [17], its effect on LPO was only assessed in this work.

The complexation of the compounds with iodine provided evidence to its possible anti-thyroid effects. Previous work showed that sertraline hydrochloride in presence of iodine led immediately to the appearance of a new CT band located at $257 \mathrm{~nm}$. This band has a $\mathrm{K}_{\mathrm{c}}$ value of $3277.48 \mathrm{~L} \mathrm{~mol}^{-1}$ that indicates strong activity (much larger than the $100 \mathrm{~L} \mathrm{~mol}^{-1}$ reference value) [17]. In this work, sequential addition of increasing concentrations of $\left(\mathrm{SerH}_{2}\right)_{2}\left[\mathrm{CuCl}_{4}\right]$ complex on iodine solution produced a reduction of the iodine band intensity but no CT band was observed. This behavior suggests that the compound has no ability to trap iodine but may act as a catalyst promoting the disappearance of iodine.

Besides the capacity of several substances containing free $\mathrm{N}-\mathrm{H}$ moiety to form CT complexes with iodine, it has also been proposed that these types of compounds can act as TPO inhibitors. Researchers suggested a possible competitive coordination with the iron center of the enzyme, which is mediated by hydrogen bonding formation through $\mathrm{N}-\mathrm{H}$ group [51]. When sertraline hydrochloride was tested on LPO as a model for TPO, inhibition behavior was observed in a dose-dependent manner (Fig. 4). The calculated $\mathrm{IC}_{50}=80 \mu \mathrm{M}$ resulted lower than the reported value for other typical antidepressants. It is worth mentioning that for the others antidepressants (desipramine, imipramine, and clomipramine among others) horseradish peroxidase [52] was used to perform the experiments. For this reason, direct comparison was not possible to achieve. However, in the cases in which the $\mathrm{IC}_{50}$ values were determined, they ranged between 3.7 and $0.81 \mathrm{mM}$. It may be noted that sertraline behaves as a dual inhibitor, capturing iodine and inhibiting the enzyme from being a good anti-thyroid agent. On the other hand, the copper complex did not show any significant LPO inhibition, hence indicating that the LPO inhibitory activity of sertraline is lost upon salt formation.

\subsubsection{Catalytic activity}

As mentioned above, previous findings showed characteristic

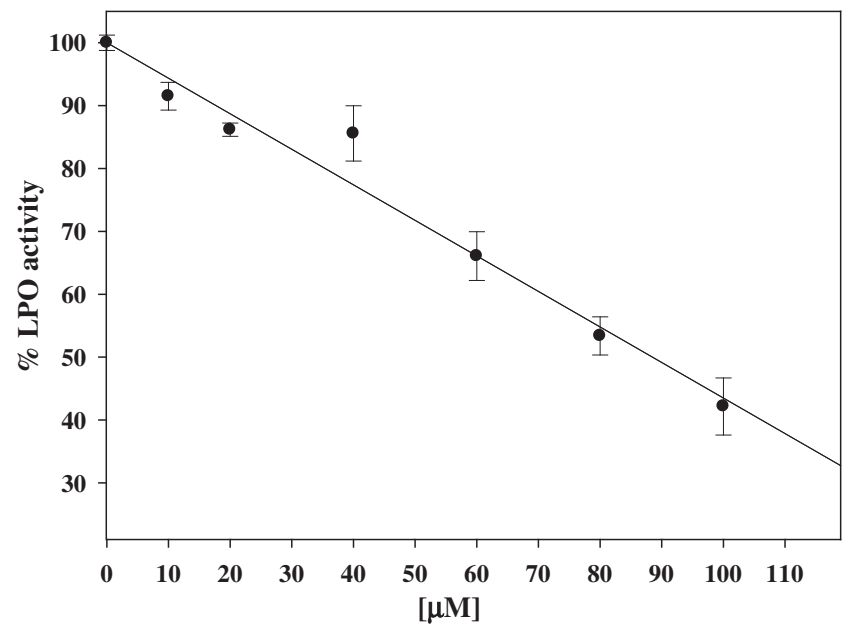

Fig. 4. Inhibition curve of sertraline on LPO-catalyzed oxidation of ABTS.

catalytic activity of tetrahalocuprate salts $[23,24]$. Furthermore, some polymer-anchored copper complex was found to be very selective for the oxidation of ethylbenzene to acetophenone [53]. Other relevant aspect is their use as pharmaceutically acceptable salts for controlling helminths and to improve growth in animals [54]. Based on this information and in the experimental observations mentioned above, it was considered to test the catalytic activity of this complex in bromination reactions simulating haloperoxidases action. Metal complexes are well-recognized models for V-haloperoxidases, especially vanadium complexes [[55].].

The mimicking peroxidase activity was evaluated according to the method proposed by Feng et al. [30] In this method, the effect of the complex on the bromination of phenol red (the organic substrate) is followed. The addition of a tetrachlorocuprate complex solution to the standard reaction of bromide (phosphate buffer $\mathrm{pH}=5.8$ ) containing phenol red produced a change in the color of the solution from yellow to blue. This was observed in the electronic UV-vis spectra as an increment of the $592 \mathrm{~nm}$ band intensity, characteristic for the bromophenol blue product, and a corresponding decrease of the $443 \mathrm{~nm}$ band intensity, due to the loss of the phenol red (Fig. 5). At first, the effect of catalyst's amount was evaluated by taking different concentrations but the reactions turned out to be too fast. For that reason, a lower amount of catalyst $(0.007 \mathrm{~g})$ was employed and the reaction conditions optimized.

For a better understanding, the bromoperoxidase mimetic activity was evaluated considering a pseudo first-order reaction. The first-order dependency on the organic substrate is demonstrated by the observed linearity of $\ln \left([A] /\left[A_{0}\right]\right) v$ s. time plots (Fig. S5), where $A$ and $A_{0}$ are the absorbances at $592 \mathrm{~nm}$, measured at times $t$ and $t=0$, respectively. Average $k$ and $\mathrm{t}_{1 / 2}$ values $\left(0.157 \pm 0.007 \mathrm{~min}^{-1}\right.$ and $4.41 \mathrm{~min}$, respectively) have been obtained from different sets of experiments confirming that the complex behaved as a bromoperoxidase-mimic compound. Peroxidase mimic action could be associated to a mechanism of antithyroid action. It consists in a indirect inhibition of the LPO enzyme. The compound does not inhibit the enzyme directly, but reduce the $\mathrm{H}_{2} \mathrm{O}_{2}$ substrate generated by thyroid oxidase enzyme avoiding the oxidation of the iron center of the LPO [31]. 
(A)

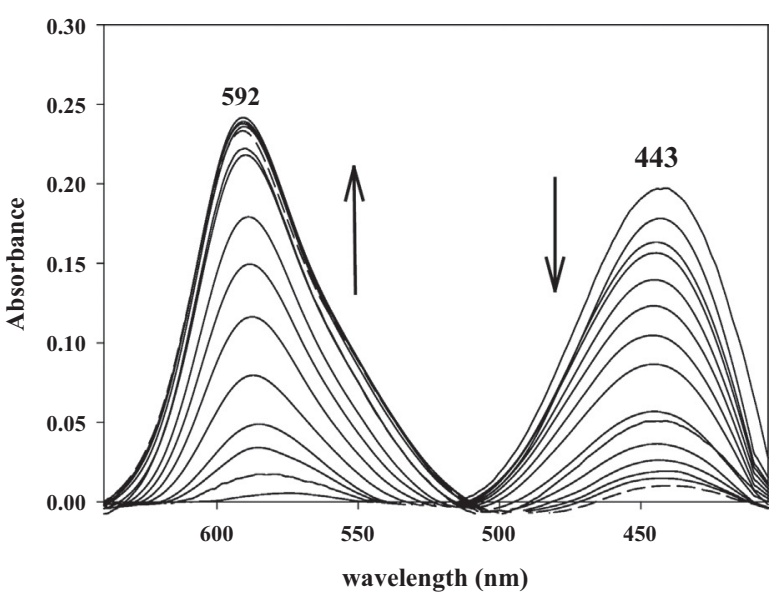

(B)

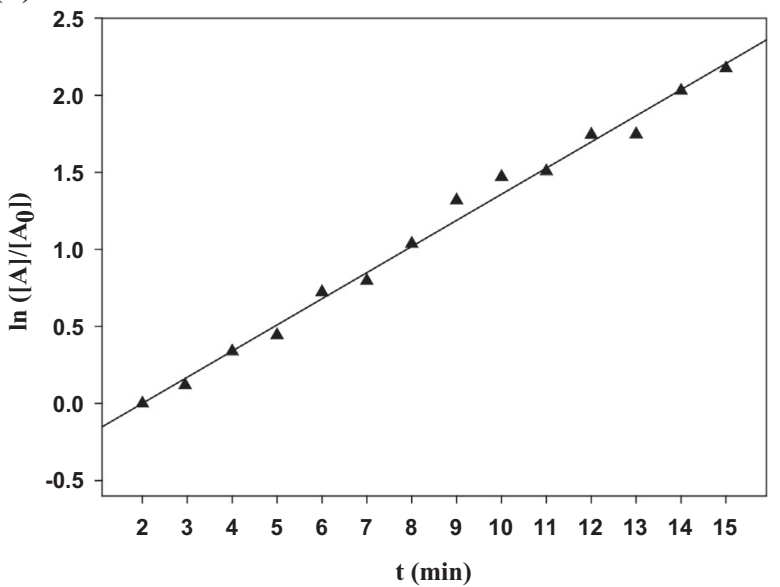

Fig. 5. Oxidative bromination of phenol red catalyzed by the copper complex $(0.04 \mathrm{mmol})$. Spectral changes at $1 \mathrm{~min}$ intervals. Spectral data taken of aliquots in $\mathrm{pH}=5.8$ (aqueous phosphate buffer), $[\mathrm{KBr}]=2 \mathrm{M}, \quad[$ phenol $\quad$ red $]=20 \mu \mathrm{M}$, $\left(\mathrm{SerH}_{2}\right)_{2}\left[\mathrm{CuCl}_{4}\right]=7.38 \mu \mathrm{M}$.

\subsubsection{Antioxidant properties}

As it was mentioned $[19,20]$, there are several evidences indicating a potential link between antidepressant and hyperthyroidism disease and oxidative stress. For that reason, SOD mimetic activity of sertraline and sertraline copper derived compound was also assessed. This determination was performed with the idea that the tested compound possible has more than one biological effect and that it could potentially act also as antioxidant. Under our experimental conditions, sertraline did not show any scavenging capacity. In Fig. 6 the antioxidant ability of $\left(\mathrm{SerH}_{2}\right)_{2}\left[\mathrm{CuCl}_{4}\right]$ complex can be appreciated. The prepared complex showed an $\mathrm{IC}_{50}$ value of $6.6 \times 10^{-6} \mathrm{M}$ and a resulting $k_{\mathrm{McCF}}$ value of $2.83 \times 10^{6} \mathrm{~mol}^{-1} \cdot \mathrm{L} \cdot \mathrm{s}^{-1}$. Even though it was not as effective as the enzyme (bovine erythrocyte SOD, $\mathrm{IC}_{50}=2.1 \times 10^{-7} \mathrm{M}$, $k_{\mathrm{McCF}}=8.5 \times 10^{8} \mathrm{~mol}^{-1} \cdot{\mathrm{L} \cdot \mathrm{s}^{-1}}^{-1}$ [29], experimental $\mathrm{IC}_{50}$ values below $20 \times 10^{-6} \mathrm{M}$ are still considered as strong SOD mimics. Thus, we conclude that the tested complex do in fact exhibits catalytic activity toward the dismutation of superoxide anions. This could be explained bearing in mind that SOD activity depends strongly on the geometry around the copper ion, being more effective in structurally flexible geometry. This can be related to the ability of the ligand to accommodate the reduced copper(I) in a tetrahedral-like or linear environment. Considering the well-known structural variability of tetrahalocuprates that can adopt square planar, distorted square planar, and tetrahedral geometries [6], it can be suggested that $\left(\mathrm{SerH}_{2}\right)_{2}\left[\mathrm{CuCl}_{4}\right]$ complex has the ability to show geometrical changes [23]. This is an

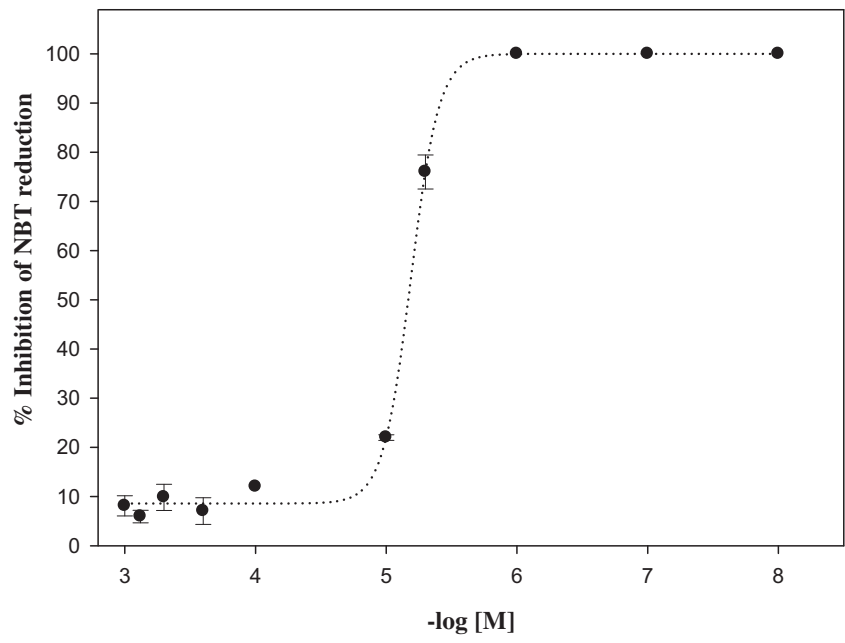

Fig. 6. Effects of $\left(\mathrm{SerH}_{2}\right)_{2}\left[\mathrm{CuCl}_{4}\right]$ on the reduction of nitroblue tetrazolium by nonenzymatically-generated superoxide (phenazine methosulfate and reduced nicotinamide adenine dinucleotide system). The values are expressed as the mean \pm SEM of at least three independent experiments.

essential characteristic for the catalysis to take place as it is the geometry of copper in the SOD enzyme that changes its distorted square pyramidal environment.

On the other hand, the complex did not display antioxidant activities against other tested radicals (DPPH • and $\mathrm{OH} \cdot$ ) (data not shown).

\subsection{In vivo assessment of potential pharmacological activities}

\subsubsection{Antidepressant activity}

The role of copper in the affective disorders has not been well established but there are some information related to its involvement in mood disorders [56]. It was suggested that, as an enzyme component (monoamine oxidase (MAO), dopamine b-hydroxylase (DBH), and tyrosine hydroxylase) it exerts influence in the pathophysiology of depression [14] and participate in some disturbances in glutamatergic transmission which are the base of glutamate hypothesis of depression [56]. Several studies were performed on copper level in depressed humans and some of them showed significantly reduced serum copper level. Literature data prompted us to research about the efficiency of copper salt as an antidepressant agent. In particular, we evaluate if this bioelement may produce a synergistic effect in the sertraline antidepressant activity as an anionic component of this new compound.

Behavioral effects produced in the forced swimming test by administration of sertraline, $\mathrm{CuCl}_{2}$ and $\left(\mathrm{SerH}_{2}\right)_{2}\left[\mathrm{CuCl}_{4}\right]$ are shown in Fig. 7.

In accordance with our previous study $[10,11]$ a 14-day treatment with antidepressant sertraline $(10.0 \mathrm{mg} / \mathrm{kg}$, p.o.) significantly decreased immobility, concomitant with an increase in swimming without modifying the climbing behavior, hence indicating an antidepressant effect (Fig. 7). On the contrary, $20 \mathrm{mg} / \mathrm{kg}$ doses of sertraline failed to alter FST behaviors.

The treatment with $\mathrm{CuCl}_{2}$ at the two-different doses dose failed to modify the immobility, swimming and the climbing behavior compared with saline controls.

Contrary to what it is observed for copper simple salt and sertraline, the $\left(\mathrm{SerH}_{2}\right)_{2}\left[\mathrm{CuCl}_{4}\right]$ complex showed dose-dependent antidepressant effect during the forced swimming test (FST) when compared with saline controls (Fig. 7). The compound produced a dose-dependent decrease in immobility and a corresponding increase in swimming without significantly affecting the frequency of climbing time. The resultant action mechanism is suggested to be similar to that of sertraline, namely a typical serotonin-selective reuptake inhibitors (SSRIs class), having in this case a more robust effect. Discarding the re-storing of 


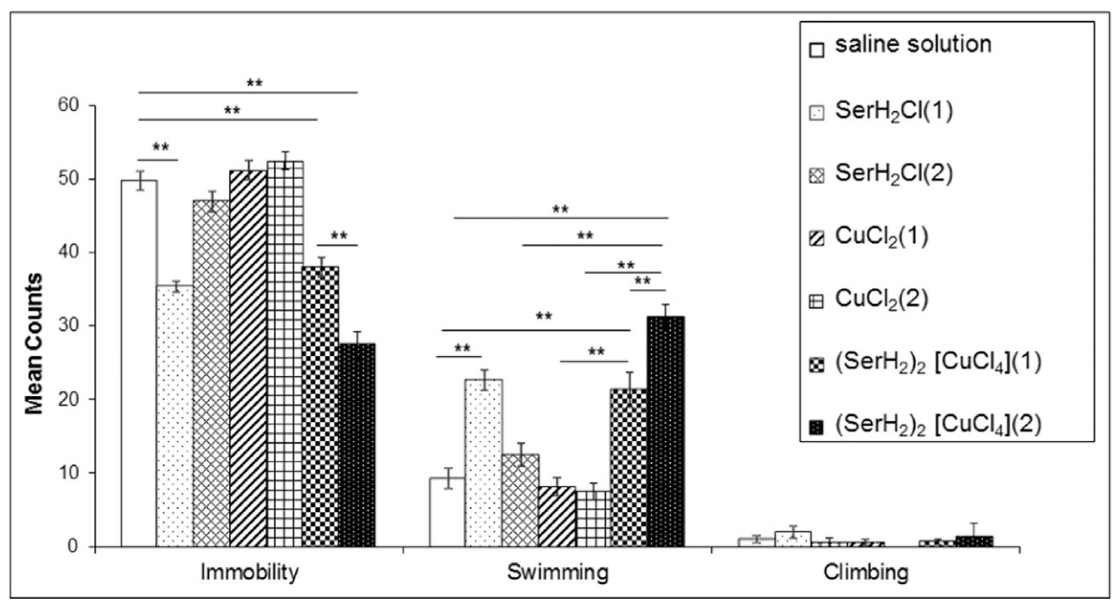

Fig. 7. Forced swimming test (FST): effects of sertraline, $\mathrm{CuCl}_{2}$ and $\left(\mathrm{SerH}_{2}\right)_{2}\left[\mathrm{CuCl}_{4}\right] \cdot 1 / 2 \mathrm{H}_{2} \mathrm{O}$ treatments on the behavior of the rats in the forced swimming test (FST). Bars represent the mean number of counts over the 5 -min period of the test ( \pm S.E.M.). ${ }^{*} P<0.05$, $* * P<0.01,5-10$ rats per group. Saline solution; $\mathrm{Cu}\left(\mathrm{CuCl}_{2}(1)\right.$ $2.70 \mathrm{mg} / \mathrm{Kg}$ and (2) $(5.40 \mathrm{mg} / \mathrm{Kg}) ; \mathrm{SerH}_{2} \mathrm{Cl}$ (sertraline): (1) $10.0 \mathrm{mg} / \mathrm{Kg}$ and (2) $20.0 \mathrm{mg} / \mathrm{Kg}$; $\left(\mathrm{SerH}_{2}\right)_{2}\left[\mathrm{CuCl}_{4}\right]$ (1): $(13.3 \mathrm{mg} / \mathrm{Kg})$ and $\left(\mathrm{SerH}_{2}\right)_{2}\left[\mathrm{CuCl}_{4}\right]$ (2): $26.6 \mathrm{mg} / \mathrm{Kg}$. Statistical analysis was carried out by one-way ANOVA followed by Bonferroni's test for multiple comparisons. copper levels because $\mathrm{CuCl}_{2}$ showed no significant effect, it can be speculated that the synergistic behavior due to the copper presence may arise from the proposed NMDA receptors inhibition [56]. This behavior is based on the chemical and biological similarity with the $\mathrm{Zn}(\mathrm{II})$ ion (valence, size, and charge and the sharing of some biological functions in the nervous system). Additional effect can be also considered arising from its proved SOD similar activity. Therefore, future studies are needed to better understand all the possible steps involved in the mechanism by which $\left(\mathrm{SerH}_{2}\right)_{2}\left[\mathrm{CuCl}_{4}\right]$ acts as an antidepressant agent.

The effect of $\mathrm{CuCl}_{2}$, sertraline $\left(\mathrm{SerH}_{2} \mathrm{Cl}\right)$, and $\left(\mathrm{SerH}_{2}\right)_{2}\left[\mathrm{CuCl}_{4}\right]$ on spontaneous locomotor activity was evaluated (Fig. $\mathrm{S} 6 \mathrm{~A}$ ). $\mathrm{CuCl}_{2}$ salt had dissimilar locomotor activity behavior. Sertraline behaved as expected. None of the treatments with $\left(\mathrm{SerH}_{2}\right)_{2}\left[\mathrm{CuCl}_{4}\right]$ showing antidepressant-like effect in the FST affected the activity levels when rats were tested in an open field chamber instead of the forced swimming cylinders during the re-test (means \pm S.E.M.). This result confirms the specificity of the FST results.

Regarding the well-known anorexigenic effect caused by sertraline, body weight gain analysis during chronic treatments with all the compounds were evaluated (Fig. S6B). Chronic treatment with sertraline induced a decrease in body weight gain in a dose-dependent manner. Body weight was significantly lower in animals treated with the higher dose of sertraline as compared with the control group. No changes in body weight were observed in rats after $\mathrm{CuCl}_{2}$ or $\left(\mathrm{SerH}_{2}\right)_{2}\left[\mathrm{CuCl}_{4}\right]$ administration. Thus, this compound additionally suppresses the anorexigenic side-effect of the parent drug, a feature that possibly constitutes an additional second clinical advantage.

\subsubsection{Analgesic properties}

Currently, there are several evidences related to the antinociceptive activity exerted by antidepressants. The analgesic effect was demonstrated in clinical studies as well as in animals submitted to different nociceptive stimuli [15]. This effect was also noted to be independent of its antidepressant effect [57]. Furthermore, copper complexes showed analgesic effects [58]. These data prompted us to consider the possibility that the combined administration of sertraline and copper in the form of the $\left(\mathrm{SerH}_{2}\right)_{2}\left[\mathrm{CuCl}_{4}\right]$ compound may have antinociceptive activity. Because of the scarce reported information about the analgesic effect of sertraline, we also included this pharmaceutical in our studies. Acute $(60 \mathrm{~min})$ and chronic (14 days) treatments were performed (Fig. 8). It has to be considered that an increase in reaction time (latency, sec) compared to basal (saline solution) is proportional to analgesic activity of the tested compounds. As it can be appreciated, in the acute treatment (see Fig. 8), sertraline $(10 \mathrm{mg} / \mathrm{kg})$ and $\mathrm{CuCl}_{2}(2.7 \mathrm{mg}$ / $\mathrm{Kg}$ ) increased the latency of licking in $30.36 \%$ and $40 \%$, respectively. On the contrary, at the same doses and after 14 days of treatment, those compounds failed to augment the response latency (Fig. S7). Interestingly, acute treatment with $\left(\mathrm{SerH}_{2}\right)_{2}\left[\mathrm{CuCl}_{4}\right]$ (Fig. 8) had a greater

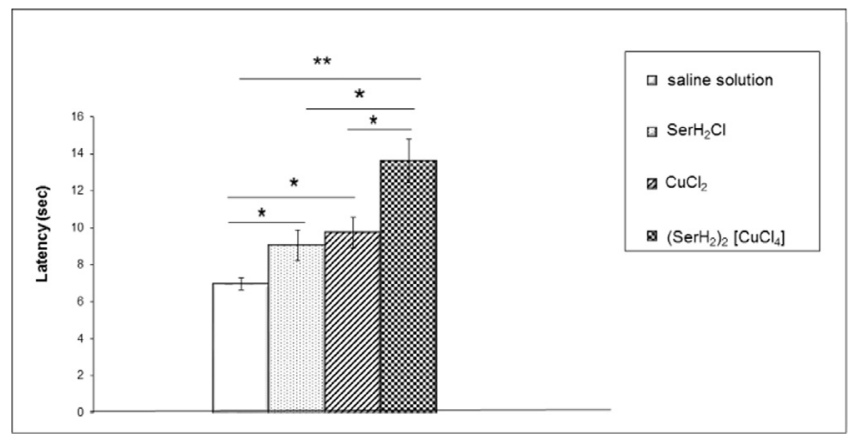

Fig. 8. Hot-plate test: influence of $\mathrm{CuCl}_{2}(2.7 \mathrm{mg} / \mathrm{Kg}), \mathrm{SerH}_{2} \mathrm{Cl}$ (sertraline, $10 \mathrm{mg} / \mathrm{Kg}$ ) and $\left(\mathrm{SerH}_{2}\right)_{2}\left[\mathrm{CuCl}_{4}\right](13.30 \mathrm{mg} / \mathrm{kg})$ on the reaction time (licking of hind paws) of rats. Acute treatment. Statistical analysis was carried out by one-way ANOVA followed by Dunnett's test.

antinociceptive effect (95.82\%) as compared with sertraline or $\mathrm{CuCl}_{2}$ acting alone, a fact that implies an additive effect. The complex maintained its effect in the chronic treatment, in contrast to that observed for the others tested compounds. The response latency increased to $76.69 \%$ when compared with the control. These findings clearly show a significantly potentiated analgesic action (synergistic behavior) in the $\left(\mathrm{SerH}_{2}\right)_{2}\left[\mathrm{CuCl}_{4}\right]$ complex. It is suggested that sustained analgesic effect may be the result of slower and prolonged gastric absorption [16] that could be explained because a greater lipophilicity. In the case of the complex, it was found better albumin affinity than for sertraline alone that favors its biological distribution (see next section). It is also proposed that the enhanced analgesic activity of copper complexes can be explained by activation of copper-dependent opioid receptors [16].

The effects of different treatments on locomotor activity are shown in Fig. S8. In the acute treatment (Fig. S8(A)), the locomotor activity increased after administration of sertraline and $\left(\mathrm{SerH}_{2}\right)_{2}\left[\mathrm{CuCl}_{4}\right] \mathrm{com}$ plex. However, locomotor activity was decreased in the rats after administration of $\mathrm{CuCl}_{2}$. In contrast, during the chronic treatment none of the compounds affected motor activity levels in the open field chamber (Fig. S8(B)).

These results suggest that, as is the case of others compounds, the analgesic effect is independent of the antidepressant activity. Furthermore, in the case of the acute treatment the increase in the locomotor activity suggested that the compound did not behave in a sedative manner, while in the chronic treatment motor activity levels did not significantly changes as it was expected [59].

At the end of the treatment period, none of the compounds affected the gain in body weight as compared with the control saline compound (Fig. S9). This is a clear advantage since some traditional analgesic compounds provoked body weight loss. 


\subsubsection{Binding affinity to albumin by fluorescence and UV-vis spectroscopies}

Serum albumin is a most important depository and transport protein of the circulatory system, as it binds a whole variety of metabolites, drugs, dyes and several others substances. Studies on the interactions between serum albumin and bioactive molecules provide insight on drug-protein binding. This type of study may have potential therapeutic applications. Bovine serum albumin (BSA) is often used as a model because of its close structural homology to human serum albumin (HSA). It is well established that the reversible binding to one or very few high-affinity sites of the albumin usually is accompanied by association constant $\left(\mathrm{K}_{\mathrm{b}}\right)$ values from $10^{4}$ to $10^{6} \mathrm{M}^{-1}$ indicating a carrierlike behavior [60]. But additionally to the primary sites, several sites of lower affinity are available. Therefore, a magnitude order of $10^{3} \mathrm{M}^{-1}$ of the binding constant value also describes the reversible character of the interaction [61]. This range suggests an improved bioavailability of the drugs increasing its solubility and modulating their delivery to cell in vivo and in vitro. Thus, these kinds of studies are relevant from the pharmacological point of view [62]. The interaction with BSA can be studied by several methodologies and fluorescence spectroscopy is one of the most frequently used.

The results of the quenching experiments from the interaction between $\left(\mathrm{SerH}_{2}\right)_{2}\left[\mathrm{CuCl}_{4}\right]$ and BSA at $25^{\circ} \mathrm{C}$ and $37^{\circ} \mathrm{C}$ are shown in Fig. S10 and in Fig. 9. It could be seen that up to a maxima concentration of $100 \mu \mathrm{M}$, the Stern-Volmer curves were linear. Consequently, the quenching type was probably single quenching (static or dynamic quenching) in this range of concentration. In this study, the values of $K_{\mathrm{sv}}$ were found to be $1.4 \times 10^{3} \mathrm{~L}^{\mathrm{mol}}{ }^{-1}$ at $25^{\circ} \mathrm{C}$ and $1.29 \times 10^{3} \mathrm{~L}^{-\mathrm{mol}^{-1}}$ at $37^{\circ} \mathrm{C}$, being the corresponding $K_{\mathrm{q}}$ values of $1.4 \times 10^{11} \mathrm{~L}^{-\mathrm{mol}^{-1}}$ and $1.29 \times 10^{11} \mathrm{~L} \cdot \mathrm{mol}^{-1}$, respectively. Since the bimolecular quenching constants $\left(K_{\mathrm{q}}\right)$ are larger than the maximum diffusion collision quenching rate constant, the quenching was not initiated from dynamic collision but from the formation of a compound. In this case, the interactions can further be interpreted by apparent static binding constant $\left(\mathrm{K}_{\mathrm{b}}\right)$ and the number of binding sites (n) can be estimated. The $\mathrm{K}_{\mathrm{b}}$ and $\mathrm{n}$ per BSA at the two temperatures were listed in Table 3.

It can be appreciated that the value of the binding constant ( $\leq 10^{3} \mathrm{M}^{-1}$ ) of the new compound is in the expected range for the binding of the antidepressants to BSA [10] (including sertraline with $\mathrm{K}_{\mathrm{b}}=40.7 \mathrm{M}^{-1}$ ). This effect represents an improvement in the uptake of the complex by the albumin working at the time required for the effective interaction of sertraline $(8 \mathrm{~h})$. Furthermore, the n-value of about 1 means that there was one independent class of binding site on the albumin for complex formation. It is worth noting that during a

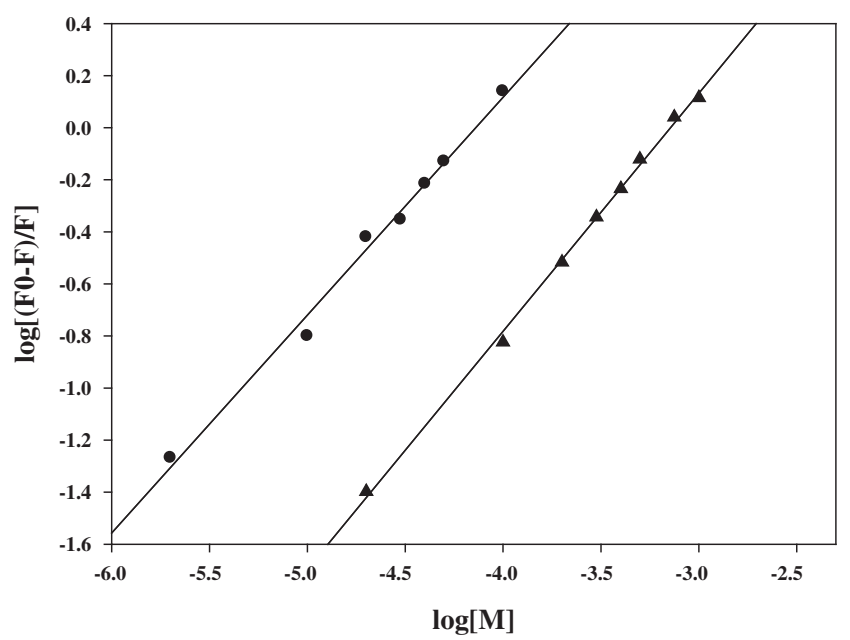

Fig. 9. $\left(\mathrm{SerH}_{2}\right)_{2}\left[\mathrm{CuCl}_{4}\right]-\mathrm{BSA}$ system: Plots of $\log \left[\left(\mathrm{F}^{0}-\mathrm{F}\right) / \mathrm{F}\right] v s$. $\log [\mathrm{Q}]$ at $(\bullet) 298 \mathrm{~K}$ and (A) $310 \mathrm{~K} . \lambda_{\text {ex }}=280 \mathrm{~nm}$. [BSA] $=6 \mu \mathrm{M}$, $\left(\mathrm{SerH}_{2}\right)_{2}\left[\mathrm{CuCl}_{4}\right]=0-100 \mu \mathrm{M}$.
Table 3

Apparent binding constants $\mathrm{K}_{\mathrm{b}}$, " $\mathrm{n}$ " binding site and relative thermodynamic parameters of the system of $\left(\mathrm{SerH}_{2}\right)_{2}\left[\mathrm{CuCl}_{4}\right]$.

\begin{tabular}{llllllll}
\hline $\mathrm{pH}$ & $\mathrm{T}(\mathrm{K})$ & $\mathrm{K}_{\mathrm{b}}\left(\mathrm{M}^{-1}\right)$ & $n$ & $\mathrm{R}^{\mathrm{a}}$ & $\begin{array}{l}\Delta \mathrm{H}_{0}(\mathrm{KJ} / \\
\mathrm{mol})\end{array}$ & $\begin{array}{l}\Delta \mathrm{G}_{0}(\mathrm{KJ} / \\
\mathrm{mol})\end{array}$ & $\begin{array}{l}\Delta \mathrm{S}_{0}(\mathrm{~J} / \\
\mathrm{mol} \cdot \mathrm{K})\end{array}$ \\
\hline 7.4 & 298 & $2,90 \times 10^{3}$ & 0,84 & 0,98 & -87 & $-19,75$ & $-225,7$ \\
& 310 & $7,47 \times 10^{2}$ & 0,91 & 0,99 & & & \\
\hline
\end{tabular}

$R^{a}$. is the correlation coefficient for the $K_{b}$ values.

DS: standard deviation.

short incubation time the binding of $\left(\mathrm{SerH}_{2}\right)_{2}\left[\mathrm{CuCl}_{4}\right]$ to $\mathrm{BSA}$ is stronger than for sertraline therefore suggesting a substantially improvement of the ability to bind albumin [10].

Following a series of studies, Ross et al. [63] proposed that the sign of the thermodynamic parameters revealed the nature of the interaction taking place during the formation of the complex between the studied compound and the albumin.

The thermodynamic parameters were calculated using Van't Hoff eq. $[38,39]$ and the results are included in Table 3 .

The $\Delta \mathrm{G}^{0}$ value reflects the possibility of the reaction, and $\Delta \mathrm{H}^{0}$ and $\Delta S^{0}$ suggest the acting forces. For temperatures varying in a small range, the $\Delta \mathrm{H}^{0}$ value can be considered as a constant.

There have been proposed four types of non-covalent interactions, namely hydrogen bonds, van der Waals, electrostatic, and hydrophobic interactions that play an important role in ligand binding to proteins. In this case, negative enthalpy and entropy changes suggest the involving of non-bonded (van der Waals) interactions and hydrogen-bond formation in low dielectric media with protonation accompanying association. In that case, it is possible to assume that metal complexation takes place mainly via van der Waals (stacking) interactions.

To support this finding, the interaction between the complex and BSA was also studied by UV-vis spectroscopy (Fig. S11). It is evident that the observed increase in the intensity of the BSA band at $280 \mathrm{~nm}$ accompanied with its blue-shift suggests a change in the opening of the structure and also the exposition of the protein residues. These changes are in concordance with the formation of the complex between the protein and the copper compound along with a decrease of the environment hydrophobicity $[38,39]$.

\section{Conclusions}

The hydrated and anhydrous forms of two new sertraline-based salt, consisting of a coordination complex anion containing $\mathrm{Cu}(\mathrm{II})$ and sertralonium cation $\left(\left(\mathrm{SerH}_{2}\right)_{2}\left[\mathrm{CuCl}_{4}\right] \cdot \frac{1}{2} \mathrm{H}_{2} \mathrm{O}\right.$ and $\left.\left(\mathrm{SerH}_{2}\right)_{2}\left[\mathrm{CuCl}_{4}\right]\right)$ have been synthesized and characterized by several physicochemical techniques. Their crystal structures were solved by X-ray diffraction methods. The sertraline molecules appear in both solid as their cationic $\left(\mathrm{SerH}_{2}{ }^{+}\right)$moiety, protonated at their amine groups, and show significant conformational flexibility. The crystal salts are further stabilized by intermolecular $>\mathrm{NH}_{2}{ }^{+} \ldots\left[\mathrm{CuCl}_{4}\right]^{2-}$ bonds and the hydrate also presents $>\mathrm{NH}_{2}{ }^{+}$... Ow and Ow-H...Cl bonds. FTIR, Raman, diffuse reflectance and UV-vis and EPR spectroscopies showed typical features of tetrachlorocuprate(II) compounds. Antimicrobial activity of the sertraline-based salts was found similar to the pharmaceutical sertraline behavior. Sertraline was able to inhibit LPO enzyme showing antithyroid activity while the copper complex neither exert any inhibitory effect nor showed ability to trap iodine. The complexes exhibit catalytic bromination activity hence indicating that they can be considered as a potential functional model of bromoperoxidase enzyme. Their catalytic activity was also demonstrated because its SOD mimic ability $\left(\mathrm{IC}_{50}=6.3 \times 10^{-6} \mathrm{M}\right)$. In vivo assessment of potential pharmacological activities showed a dose-dependent antidepressant effects of the $\left(\mathrm{SerH}_{2}\right)_{2}\left[\mathrm{CuCl}_{4}\right]$ complex suppressing the anorexigenic side-effect caused by sertraline. Acute and chronic treatments in the analgesic test 
showed increment of $30.36 \%$ to sertraline $(10 \mathrm{mg} / \mathrm{kg}$ ) and a $95.82 \%$ value to $\left(\mathrm{SerH}_{2}\right)_{2}\left[\mathrm{CuCl}_{4}\right]$ in the latency of licking therefore indicating a considerable analgesic action. The evaluation of the BSA binding ability is in agreement with complex formation via van der Waals (stacking) interactions.

It is shown that the combination of the sertraline drug with copper produced a synergistic effect on the antidepressant activity, generating an antianorexigenic effect, but also on the analgesic effect, the catalytic activities against the superoxide anion and as bromoperoxidase mimic compound.

\section{Abbreviations}

$\mathrm{SerH}_{2} \mathrm{Cl}$ Sertraline hydrochloride

$\mathrm{SerH}_{2}{ }^{+}$Sertralonium cation

$\left(\mathrm{SerH}_{2}\right)_{2}\left[\mathrm{CuCl}_{4}\right]$ Sertralonium tetrachlorocuprate(II)

ABTS 2,2'-Azinobis(3-ethyl-benzothiazoline-6-sulfonic acid) diammonium salt

AcP Acid phosphatase

ALP Alkaline phosphatase

BSA Bovine serum albumin

DMSO Dimethyl sulfoxide

DPPH • 1,1-Diphenyl-2-picrylhydrazyl radical

EDTA Ethylenediaminetetraacetic acid

NADH Reduced nicotinamide adenine dinucleotide

NBT nitroblue tetrazolium

LPO lactoperoxidase from bovine milk

PMS phenazine methosulfate

Tris-HCl Tris(hydroxymethyl)aminomethane hydrochloride

\section{Acknowledgments}

This work was supported by CONICET (PIP 1529 and 0611), ANPCyT (PME06 2804, PICT06 2315 and PICT13-0569), UNLP (X 739), CICPBA (813/13), and UNLAR (27/A624) of Argentina. GAE, OEP, EGF are Research Fellows of CONICET. NM is a fellowship holder from CONICET. JEP and PAMW are Research Fellows of CICPBA, Argentina.

\section{Appendix A. Supplementary data}

$\left(\mathrm{SerH}_{2}\right)_{2}\left[\mathrm{CuCl}_{4}\right]^{-1 / 2} \mathrm{H}_{2} \mathrm{O}$ (CCDC 1519924): and $\left(\mathrm{SerH}_{2}\right)_{2}\left[\mathrm{CuCl}_{4}\right]$ (CCDC 1519925): Tables: bond lengths and angles (Tables S1a and $\mathrm{S} 1 \mathrm{~b})$, atomic coordinates and equivalent isotropic displacement parameters (Tables S2a and S2b), anisotropic displacement parameters (Tables S3a and S3b), hydrogen coordinates and isotropic displacement parameters (Tables S4a and S4b), torsion angles (Tables S5a and S5b), hydrogen bond distances and angles (Tables S6a and S6b). Figures: FTIR spectra (Fig. S1), Raman spectra (Fig. S2), Reflectance diffuse spectrum (Fig. S3), Electronic spectra (Fig. S4). Plot of $\ln \left([A] /\left[A_{0}\right]\right) v s$. time (Fig. S5). Effects of sertraline $\left(\mathrm{SerH}_{2} \mathrm{Cl}\right), \mathrm{CuCl}_{2}$ and $\left(\mathrm{SerH}_{2}\right)_{2}\left[\mathrm{CuCl}_{4}\right]$ treatments on spontaneous locomotor activity (Fig. S6A) and weight gain of rats (FST test) (Fig. S6B), Hot-plate test (Fig. S7), Open Field test (OFT) (Fig. S8), Effects of $\mathrm{SerH}_{2} \mathrm{Cl}, \mathrm{CuCl}_{2}$ and $\left(\mathrm{SerH}_{2}\right)_{2}\left[\mathrm{CuCl}_{4}\right]$ treatments on weight gain of rats (analgesic test) (Fig. S9), $\left(\mathrm{SerH}_{2}\right)_{2}\left[\mathrm{CuCl}_{4}\right]$-BSA system: Plots of $\mathrm{F}^{0} / \mathrm{F}$ vs. [Q] (Fig. S10), Electronic spectra: $200-375 \mathrm{~nm}$ region (albumin interaction) (Fig. S11). Supplementary data associated with this article can be found in the online version, at doi: http://dx.doi.org/10.1016/j.jinorgbio.2017.05. 012.

\section{References}

[1] C. Orvig, M.J. Abrams, Chem. Rev. 99 (1999) 2201-2204.

[2] D.C. Crans, T.J. Meade, Inorg. Chem. 52 (2013) 12181-12183.

[3] X.-Q. Zhou, Y. Li, D.-Y. Zhang, Y. Nie, Z.-J. Li, W. Gu, X. Liu, J.-L. Tian, S.-P. Yan, Eur. J. Med. Chem. 114 (2016) 244-256.
[4] S. Medicia, M. Peana, V.M. Nurchi, J.I. Lachowicz, G. Crisponi, M.A. Zoroddua, Coord. Chem. Rev. 284 (2015) 329-350.

[5] S. Weintraub, Y. Moskovitz, O. Fleker, A.R. Levy, A. Meir, S. Ruthstein, L. Benisvy, A. Gruzman, J. Biol. Inorg. Chem. 20 (2015) 1287-1298.

[6] H.M. Mande, P.S. Ghalsasi, A. Navamoney, Polyhedron 91 (2015) 141-149.

[7] J.L. Wikaira, C.P. Landee, S.J. Ludy, M.M. Turnbull, Polyhedron 52 (2013) $770-780$.

[8] F.F. Awwadi, S.F. Haddad, J. Mol. Struct. 1020 (2012) 28-32.

[9] F.T. Wadsworth, C.G. McAlister. 1970, (Patent US3758619).

[10] G.E. Escudero, C.H. Laino, G.A. Echeverría, O.E. Piro, N. Martini, A.N. Rodríguez, J.J. Martínez Medina, L.L. López Tévez, E.G. Ferrer, P.A.M. Williams, Chem. Biol. Interact. 249 (2016) 46-55.

[11] G.E. Escudero, C.H. Laino, N.Martini, G.A. Echeverría, O.E. Piro, P.A.M. Williams, E.G. Ferrer. 2015, (Patent Application No. 20150103320-Argentine).

[12] G.E. Escudero, N. Martini, K. Jori, N. Jori, N.R. Maresca, C.H. Laino, L.G. Naso, P.A.M. Williams, E.G. Ferrer, J. Enzyme Inhib. Med. Chem. 31 (2016) 1-7.

[13] K. Młyniec, C. Linzi Davies, I. Gómez de Agüero Sánchez, K. Pytka, B. Budziszewska, G. Nowak, Pharmacol. Rep. 66 (2014) 534-544.

[14] K. Młyniec, M. Gaweł, U. Doboszewska, G. Starowicz, K. Pytka, C.L. Davies, B. Budziszewska, Pharmacol. Rep. 67 (2015) 187-194.

[15] I. Korzeniewska-Rybicka, A. Plaznik, Pharmacol. Biochem. Behav. 59 (1998) $331-338$.

[16] S. Okuyama, S. Hashimoto, H. Aihara, W.M. Willingham, J.R. Sorenson, Agents Actions 21 (1987) 130-144.

[17] G.E. Escudero, V. Ferraresi Curotto, C.H. Laino, R. Pis Diez, P.A.M. Williams, E.G. Ferrer, Spectrochim. Acta A Mol. Biomol. Spectrosc. 104 (2013) 271-279.

[18] N.M. Urquiza, M.S. Islas, S.T. Ariza, N. Jori, J.J. Martínez Medina, M.J. Lavecchia, L.L. López Tévez, L. Lezama, T. Rojo, P.A.M. Williams, E.G. Ferrer, Chem. Biol. Interact. 229 (2015) 64-72.

[19] V. Bacic-Vrca, F. Skreb, I. Cepelak, L. Mayer, Z. Kusic, B. Petres, Clin. Chem. Lab. Med. 43 (2005) 383-388.

[20] M. Maes, P. Galecki, Y.S. Chang, M. Berk, Prog. Neuropsychopharmacol. Biol. Psychiatry 35 (2011) 676-692.

[21] G. Borkow, J. Gabbay, Curr. Chem. Biol. 3 (2009) 272-278.

[22] J.L. Muñoz-Bellido, S. Muñoz-Criado, J.A. García-Rodríguez, Int. J. Antimicrob. Agents 14 (2000) 177-180.

[23] D.W. Smith, Coord. Chem. Rev. 21 (1976) 93-158.

[24] C. Mcalister, F. Wadsworth. 1970, (United States Patent: US3758619).

[25] M. Tamura, J.K. Kochi, Bull. Chem. Jpn. 44 (1971) 3063-3073.

[26] CrysAlisPro, Oxford Diffraction Ltd., 2009, (Version 1.171.33.48 (release 15-092009 CrysAlis171.NET)).

[27] G.M. Sheldrick, Acta Crystallogr. A64 (2008) 112-122.

[28] G. Roy, G. Das, G. Mugesh, Inorg. Chim. Acta 360 (2007) 303-316.

[29] N.M. Urquiza, M.S. Islas, M.L. Dittler, M.A. Moyano, S.G. Manca, L. Lezama, T. Rojo, J.J. Martinez Medina, M. Diez, L. Lopez Tevez, P.A.M. Williams, E.G. Ferrer, Inorg. Chim. Acta 405 (2013) 243-251.

[30] X.D. Feng, R. Zhang, X.Y. Wang, X.X. Zhang, J.X. Wang, Y.H. Xing, L.X. Sun, Polyhedron 90 (2015) 69-76.

[31] A.P. Ramos Costa, C. Vieira, L.O.L. Bohner, C. Felisbino Silva, E.C. da Silva Santos, T.C. Monteiro De Lima, C. Lino-de-Oliveira, Prog. Neuro-Psychopharmacol. Biol. Psychiatry 45 (2013) 150-155.

[32] R.D. Porsolt, G. Anton, N. Blavet, M. Jalfre, Eur. J. Pharmacol. 47 (1978) 379-391.

[33] P. Willner, Psychopharmacology (Berlin) 83 (1984) 1-16.

[34] J.P. Rénéric, M. Bouvard, L. Stinus, Behav. Brain Res. 136 (2002) 521-532.

[35] F.E. D'Amour, D.L.J. Smith, Pharmacol. Exp. Ther. 72 (1941) 74-79.

[36] S. Wieland, I. Lucki, Psychopharmacol. 101 (1990) 497-504.

[37] J. Archer, Anim. Behav. 21 (1973) 205-235.

[38] N.M. Urquiza, L.G. Naso, S.G. Manca, L. Lezama, T. Rojo, P.A.M. Williams, E.G. Ferrer, Polyhedron 31 (2012) 530-538.

[39] M. Shahlaei, B. Rahimi, A. Nowroozi, M.R. Ashrafi-Kooshk, Chem. Biol. Interact. 242 (2015) 235-246.

[40] L.J. Farrugia, J. Appl. Crystallogr. 30 (1997) 565-568.

[41] K. Ravikumar, B. Sridhar, M.N. Bhanu, Acta Crystallogr. Sect. E: Struct. Rep. Online 62 (2006) o565-0567.

[42] F. Caruso, A. Besmer, M. Rossi, Acta Crystallogr. Sect. C: Cryst. Struct. Commun. 55 (1999) 1712-1714.

[43] O. Almarsson, M.B. Hickey, M.L. Peterson, S.L. Morissette, S. Soukasene, C. McNulty, M. Tawa, J.M. MacPhee, J.F. Remenar, Cryst. Growth Des. 3 (2003) 927-933.

[44] Q. He, S. Rohani, J. Zhu, H. Goma, Chirality 24 (2012) 119-128.

[45] Q. He, S. Rohani, J. Zhu, H. Goma, Cryst. Growth Des. 10 (2010) 1633-1645.

[46] A. Winter, A. Zabel, P. Strauch, Int. J. Mol. Sci. 13 (2012) 1612-1619.

[47] B. Bleaney, K.D. Bowers, Proc. R. Soc. London, Ser. A 214 (1952) 451-465.

[48] W.J. Geary, Coord. Chem. Rev. 7 (1971) 81-122.

[49] H. Liu, W. Yang, W. Zhou, Y. Xu, J. Xie, M. Li, Inorg. Chim. Acta 405 (2013) $387-394$.

[50] W.-H. Sheng, C.-C. Hung, Y.-C. Chen, C.-T. Fang, S.-M. Hsieh, S.-C. Chang, W. C. Hsieh, OJ Med. 92 (1999) 455-461.

[51] G. Roy, P.N. Jayaram, G. Mugesh, Chem. Asian. J. 8 (2013) 1910-1921.

[52] A. Rousseau, F. Comby, J. Buxeraud, C. Raby, Biol. Pharm. Bull. 19 (1996) 726-728.

[53] M.R. Maurya, S. Sikarwar, T. Joseph, P. Manikandan, S.B. Halligudi, React. Funct Polym. 63 (2005) 71-83.

[54] R.L. Klingbail. 1968, (United States Patent: US3408444).

[55] A.G.J. Ligtenbarg, R. Hage, B.L. Fering, Coord. Chem. Rev. 237 (2003) 89-101.

[56] K. Styczeń, M. Sowa-Kućma, M. Siwek, D. Dudek, W. Reczyński, P. Misztak, 
B. Szewczyk, R. Topór-Mądry, W. Opoka, G. Nowak, Biol. Trace Elem. Res. 174 (2016) 287-293.

[57] R. Rodrigues-Filho, R.N. Takahashi, Int. J. Neuropsychopharmacol. 2 (1999) 263-269.

[58] Y.E. Sherif, M.A. Gouda, A.A. El-Asmy, Med. Chem. Res. 24 (2015) 3853-3862.

[59] G.E. Escudero, C.B. Romañuk, M.E. Toledo, M.E. Olivera, R.H. Manzo, C.H. Laino, J.
Pharm. Pharmacol. 67 (2015) 1251-1262.

[60] N. Cacita, S. Nikolaou, J. Lumin. 69 (2016) 115-120.

[61] Y. Zhang, S. Shi, X. Sun, X. Xiong, M. Peng, J. Inorg. Biochem. 105 (2011) 1529-1537.

[62] J. Lin, Y. Liu, M. Chen, H. Huang, J. Lumin. 155 (2014) 39-46.

[63] P.D. Ross, S. Subramanian, S. Biochem. 20 (1981) 3096-3102. 